\title{
Article \\ Symmetric Reciprocal Symbiosis Mode of China's Digital Economy and Real Economy Based on the Logistic Model
}

\author{
Guoteng $X u^{1, *}$, Tingjie $\mathrm{Lu}^{1}$ and Yiman Liu ${ }^{2}$ \\ 1 School of Economics and Management, Beijing University of Posts and Telecommunications, \\ Beijing 100876, China; lutingjie@bupt.edu.cn \\ 2 Faculty of Law, The Chinese University of Hong Kong, Hong Kong 999077, China; \\ mandyliuyiman@link.cuhk.edu.hk \\ * Correspondence: xgtbupt@bupt.edu.cn; Tel.: +86-158-1053-0314
}

Citation: Xu, G.; Lu, T.; Liu, Y Symmetric Reciprocal Symbiosis Mode of China's Digital Economy and Real Economy Based on the Logistic Model. Symmetry 2021, 13, 1136. https://doi.org/10.3390/ sym13071136

Academic Editors: Juan Luis García Guirao and José Carlos R. Alcantud

Received: 21 April 2021

Accepted: 21 June 2021

Published: 25 June 2021

Publisher's Note: MDPI stays neutral with regard to jurisdictional claims in published maps and institutional affiliations.

Copyright: (c) 2021 by the authors. Licensee MDPI, Basel, Switzerland. This article is an open access article distributed under the terms and conditions of the Creative Commons Attribution (CC BY) license (https:// creativecommons.org/licenses/by/ $4.0 /)$.

\begin{abstract}
The convergence of the digital economy and real economy is an irreversible trend. This article uses the adjusted Logistic coevolution Model as the main tool to study the interaction factors in the convergence concentrating on conducting the empirical research by using four dimensions data from 2005 to 2019 in China to calculate the intrinsic growth rate, the maximum environmental capacity, the coevolution factors and other key indicators. The study could further simulate and predict the coevolution of the digital economy and real economy under various modes, in attempt to explore an objective reference and theoretical basis for the convergence in China, which could help to fill the research gap to some extent.
\end{abstract}

Keywords: industry convergence; digital economy; real economy; logistic model; asymmetric reciprocal symbiosis mode; symmetric reciprocal symbiosis mode

\section{Introduction}

Since the 21st century, digital technology has entered a new round of accelerated development. The 5G, Big Data, Artificial Intelligence, Internet of Things, Cloud Computing, Blockchain, and other technologies have reconstructed the material foundation of the Information Age and can be found widely in various industries. The world has entered a new era characterized by an intelligent, data-driven, learning economy [1]. The digital economy is a series of economic activities with digital knowledge and information as the key production factors, modern information networks as a crucial carrier and the effective use of digital technology as an important driving force for efficiency improvement and economic structure optimization [2-5]. The digital economy has gradually extended from virtual space to physical space, which has brought about new changes in innovation model, cost structure, competitive advantage and market demand of the traditional industry, as well as has provided new opportunities for the development of the real economy [6]. In the process of the high-speed development of the digital economy, it becomes more and more prominent for the convergence between the digital economy and real economy in various aspects, for example, technology, production, and circulation. Meanwhile, the development of convergence show more obvious characteristics of the coevolution (such as causal relationship, nonlinearity, and path dependence). Therefore, this article summarizes the previous researches relating to the coevolution to construct a growth model based on a well-known Logistic model in consideration of the convergence. It further analyzes the parameter estimation of the coevolution factors between the digital economy and real economy (including primary, secondary and tertiary industries), and then obtains a quantifiable parameter measurement method. Moreover, the official statistical data in Mainland China from 2005 to 2019 is adopted as the original data to calculate the intrinsic growth rate, maximum environmental capacity, and other factors in order to obtain the coevolution law of China's digital economy and real economy. On the basis of empirical study, the growth 
model constructed in this article simulates and predicts the coevolution trend under the seven evolution modes so as to provide an objective reference and theoretical basis for the in-depth convergence of China's digital economy and real economy.

\section{Literature Overview}

\subsection{The Characteristics of Digital Economy}

In the development process, the digital economy has three notable characteristics. First, data becomes a new factor of production. The main body of social economic activities participates in the online and offline convergence of economic and social activities through digital infrastructure, which promotes the expansion of results of economic activities from the physical level to the digital level and accumulates a large amount of data that could be used to reduce transaction costs or improve production efficiency. Furthermore, it would bring new impetus to the sustainable development of society and economy through the use of big data, cloud computing, artificial intelligence and other digital technologies to deeply explore the "knowledge" and "value" in the data. Second, the digital economy has become a new basic industry. According to OECD (2017) statistics, the ICT sector is still a key driver of innovation, accounting for the largest share of OECD business expenditure on research and development, as well as for more than one-third of the total patent applications worldwide [7]. Therefore, the technological foundation of the digital economy is the ICT technology cluster with the characteristics of strong penetration and convergence. Third, the Internet of Everything is an important material foundation of the digital economy. Universal digital technology services provide a foundation for the convergence and development of the digital economy and real economy, enabling the rapid spread of large-scale information technology revolutions and forming a positive spillover effect on economic growth. More importantly, in accordance with "Metcalfe's Law", as the number of connected users and devices increases, the value of the digital economy will exhibit a network effect, i.e., exponential growth [8].

It could be identified that the degree of the convergence continues to enhance while the digital economy is growing rapidly. The research on the convergence mechanism will have great strategic significance for promoting social and economic development in the digital era.

\subsection{Overview of Industrial Convergence Theory}

Since the European Commission published "Green Paper on the Convergence of the Telecommunications, Media, and Information Technology Sectors, and the Implications for Regulation" in 1997, a large number of discussions on industry convergence have been explored in the foreign academics. For example, Yoffie (1997) suggested that the essence of industry convergence was the recombination of enterprises through digital technology. He introduced the well-known CHESS model to rethink traditional approaches to convergence, which represented respectively: creative combinations, horizontal solutions, externalities and standards, scale and bundling, and new production techniques called system-focused development [9]. The Japanese scholar Masu Ukusa (2001) further broadened the scope of research on industry convergence and found that industry convergence could lower the barrier between industries through technological innovation and government deregulation [10]. Strikingly, Curran et al $(2010,2011)$ established a theoretical framework for the evolution process of industry convergence, concentrating on monitoring convergence through patent indicators, covering all steps of convergence-scientific, technological, and market convergence, which provided an important theoretical and practical basis for studying the convergence of the digital economy and real economy [11,12].

The research on industry convergence started comparatively late in China, starting in the 1990s. As the phenomena of blurring industry boundaries has become increasingly prominent and powerful, the perspective of industry convergence has been broadened as well as the depth of research has been continuously enhanced. For instance, $\mathrm{Yu}$ and $\mathrm{Li}(1997,2003,2004)$ proposed the industry convergence among the three industries and 
the three-stage convergence process (i.e., industry-independent development stage, industry convergence evolution stage, and deep industry convergence stage), which was accompanied by significant technological innovation penetration [13-15]. Moreover, Xie et al. $(2006,2011,2017)$ focused on the cost and benefit issues as well as constructed the technical efficiency model from the perspective of convergence of informatization and industrialization. It was argued that the participation of IT companies in investing and operating traditional industries was a concrete manifestation of the convergence [16-18].

It could be concluded that the current research on the mechanism, level, and influencing factors of convergence between the digital economy and real economy is still in its infancy after reviewing the researches on industrial convergence in China and overseas.

\subsection{Overview of Industrial Coevolution Theory}

The theory of coevolution continues to play an important role in studying the methods of industrial convergence. For example, Nelson (1994) revised the classic economic growth model from the perspective of coevolution and combined two broad bodies of the evolutionary theory for the first time. He considered "punctuated equilibrium" before concluding with a consideration of two economic developmental implications [19]. Murmann (2003) adopted the theory of coevolution to compare the development process of dye industry in the United Kingdom, Germany, and the United States, as well as gave a precise definition of the term coevolution, namely: "two evolving populations coevolve if and only if they both have a significant causal impact on each other's ability to persist. Such causal influence can proceed through two avenues: by altering the selection criteria or by changing the replicative capacity of individuals in population without necessarily altering the selection criteria" [20].

It could be found that the characteristics of coevolution include: First, there is a twoway or multi-directional causal relationship in the process of evolution. When only two subjects evolve, there must be a two-way causal relationship; otherwise, the two would not be a coevolution relationship. In the case of the evolution of multiple subjects, one interactor may have a causal relationship with multiple interactors, and thus there is a multidirectional causal relationship. In the complex relationship, the change of any variable may be caused by the causal relationship between multiple variables [21]. The second characteristic is nonlinearity. Coevolution is composed of multiple continuous feedback paths, while the complex interaction between variables makes it impossible to describe the relations between the populations as a simple linear relationship. Therefore, the evolution of one organization may also cause unexpected changes in other organizations [22]. The third is the significant path dependence. The coevolution process between populations has certain path and historical dependence characteristics. That is, a single population cannot be determined by its environment when facing evolutionary decisions. Thus, it may have a fixed evolution trajectory for a long time [23].

Under the background of accelerating the convergence between the digital economy and real economy, we could find that the studies on the convergence mechanism take qualitative analysis as the core, and there are less quantitative researches. Therefore, we need to conduct more quantifiable empirical research to further explore the internal mechanism of the convergence. Meanwhile, the basic characteristics of the coevolution theory are similar to those of the convergence between the digital economy and real economy as discussed earlier. Accordingly, it is feasible to use the theory of coevolution to study the convergence mechanism between the digital economy and real economy.

\section{Research Methodology}

\subsection{Logistic Evolution Model}

The Logistic model was first proposed by Belgian mathematician Pierre François Verhulst (1845) when studying the relationship between population growths [24]. The original model is:

$$
P(t)=\frac{P_{0} \times e^{r t}}{1+\frac{P_{0} \times\left(e^{r t}-1\right)}{P_{m}}}
$$




$$
P_{0}=P\left(t_{0}\right)
$$

in which $P(t)$ denotes the population density at the time $t, r$ is the natural growth rate of the population, and $P_{m}$ is the maximum capacity that can be achieved due to external environmental constraints when the population density is $t \rightarrow \infty$. $t_{0}$ denotes the initial time of the population evolution and $P\left(t_{0}\right)$ is the maximum allowable environmental capacity when $t=t_{0}$ (i.e., initial situation). The original Logistic model probability distribution could be obtained by simulation in Figure 1:

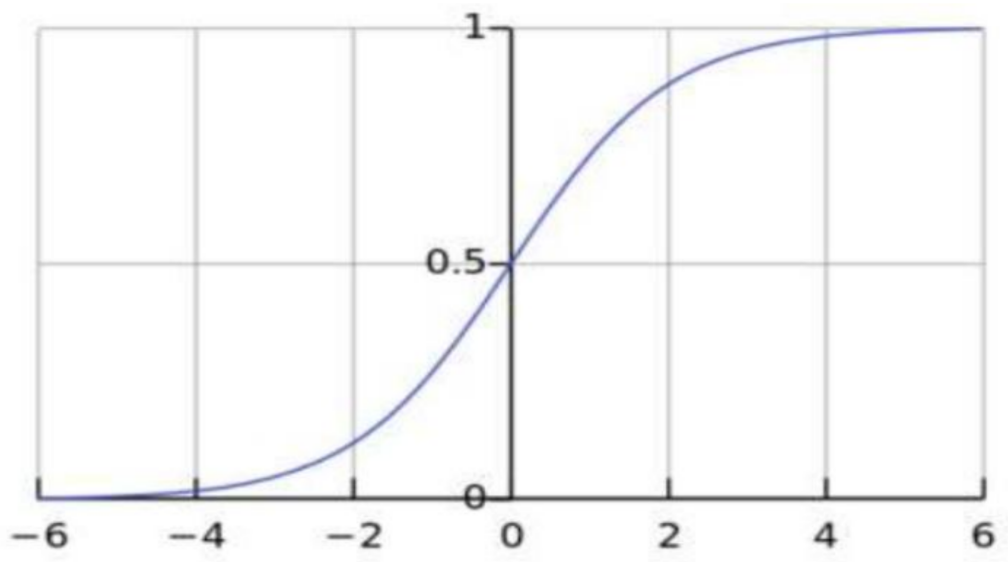

Figure 1. Probability distribution diagram of the original logistic model.

As shown in Figure 1, the probability distribution of the model basically conforms to the industrial evolution (the five stages of development theory suggested by Gort and Klepper in 1982) [25]. After further simplification, the original Logistic model could be transformed into a basic growth equation:

$$
\left\{\begin{array}{c}
\frac{d P(t)}{d t}=r\left[1-\frac{P(t)}{P_{m}}\right] P(t) \\
P_{0}=P\left(t_{0}\right)
\end{array}\right.
$$

in which $1-\frac{P(t)}{P_{m}}$ denotes the retardation effect. As the population size is closer to the maximum capacity of the environment, its potential growth space is smaller, which conforms to the law of industrial evolution in reality. It could be observed from Equation (3) that two equilibrium points, i.e., $(0,0)$ and $\left(+\infty, P_{m}\right)$, can be obtained when $\frac{d P(t)}{d t}=0$. From the perspective of the second derivative of $P(t)$ (i.e., $\left.\frac{d^{2} P(t)}{d t^{2}}=r\left[1-\frac{2 P(t)}{P_{m}}\right] d P(t) / d t\right)$, when $P(t)<P_{m} / 2$, then $\frac{d^{2} P(t)}{d t^{2}}>0$; and the population size increases rapidly as $r$ increases; conversely, when $(t)>P_{m} / 2$, the growth rate of population size slows down. As a result, the Logistic model has "three-peirod" growth characteristics: The first is the initial period, the second is the growth period, and the third is the mature period. The growth curve is as shown in Figure 2:

\subsection{Model Construction}

We suppose the population density of the digital economy and real economy in year $t$ are $P_{1}(t)$ and $P_{2}(t)$; the natural growth rates are $r_{1}$ and $r_{2}$, respectively; and the maximum growth capacities in the external environment are $P_{m 1}$ and $P_{m 2}$ respectively. Moreover, $\beta_{12}$ is the coevolution impact factor of the real economy to the digital economy, while $\beta_{21}$ is the coevolution impact factors of the digital economy to real economy in the coevolution process. $\beta_{12}$ and $\beta_{21}$ denote the mutual promotion or hindering effect of the two economies in the growth process. In accordance with Equation (3), the newly constructed/adjusted growth models of the digital economy and real economy are as follows: 


$$
\left\{\begin{array}{l}
\frac{d P_{1}(t)}{d t}=r_{1} P_{1}(t)\left[1-\frac{P_{1}(t)}{P_{m 1}}+\beta_{12} \times \frac{P_{2}(t)}{P_{m 2}}\right] \\
\frac{d P_{2}(t)}{d t}=r_{2} P_{2}(t)\left[1-\frac{P_{2}(t)}{P_{m 2}}+\beta_{21} \times \frac{P_{1}(t)}{P_{m 1}}\right]
\end{array}\right.
$$

It could be identified from Equation (4) that the value of $\beta_{12}$ and $\beta_{21}$ would affect the population growth rate of the digital economy and real economy. According to the value range of $\beta_{12}$ and $\beta_{21}$, this article divides the coevolution between the two populations into seven modes based on Pang Bohui's classification method [26]. The corresponding value range for various evolution modes are as shown in Table 1.

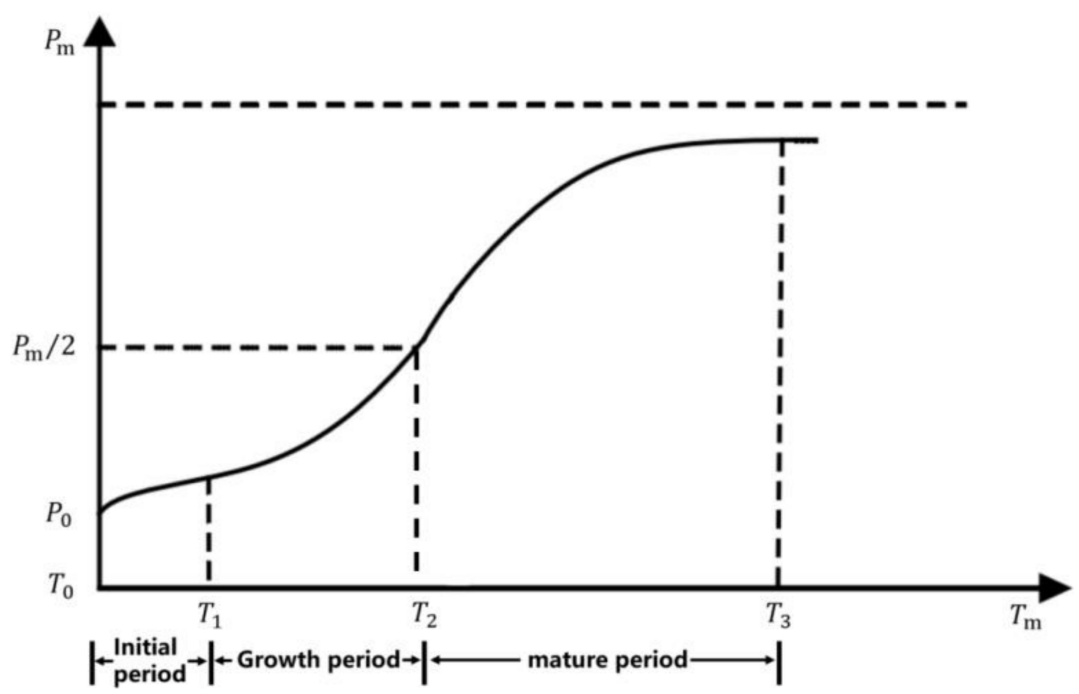

Figure 2. Logistic growth curve and the divisions of each stage.

Table 1. Classification of coevolution modes between the digital economy and real economy.

\begin{tabular}{|c|c|c|c|}
\hline Number & Value & Mode & Characteristics \\
\hline 1 & $\beta_{12}=0, \beta_{21}=0$ & Independent & $\begin{array}{l}\text { Two economies develop independently and there is no symbiotic } \\
\text { relationship. }\end{array}$ \\
\hline 2 & $\beta_{12}<0, \beta_{21}<0$ & Competition & Digital economy and real economy compete for the resources. \\
\hline 3 & $\begin{array}{l}\beta_{12}<0 \beta_{21}>0 \\
\beta_{12}>0, \beta_{21}<0\end{array}$ & Parasitism & One side achieves growth while restraining the other side's growth \\
\hline 4 & $\begin{array}{l}\beta_{12}=0, \beta_{21}>0 \\
\beta_{12}>0, \beta_{21}=0\end{array}$ & Commensalism symbiosis & $\begin{array}{l}\text { One side's growth drives the other side's growth, yet other side's } \\
\text { growth does not promote itself. }\end{array}$ \\
\hline 5 & $\begin{array}{l}\beta_{12}=0, \beta_{21}<0 \\
\beta_{12}<0, \beta_{21}=0\end{array}$ & $\begin{array}{l}\text { Reverse commensalism } \\
\text { symbiosis }\end{array}$ & $\begin{array}{l}\text { One side's growth restricts the growth of the other side while the } \\
\text { growth of the other side does not promote itself. }\end{array}$ \\
\hline 6 & $\begin{array}{l}\beta_{12}>0, \beta_{21}>0 \\
\beta_{12} \neq \beta_{21}\end{array}$ & $\begin{array}{l}\text { Asymmetric reciprocal } \\
\text { symbiosis }\end{array}$ & $\begin{array}{l}\text { When one side achieves growth to drive the growth of the other } \\
\text { side, the growth of the other side will drive the growth of itself, } \\
\text { but the driving effect is asymmetric. }\end{array}$ \\
\hline 7 & $\begin{array}{c}\beta_{12}>0, \beta_{21}>0 \\
\beta_{12}=\beta_{21}\end{array}$ & $\begin{array}{l}\text { Symmetric reciprocal } \\
\text { symbiosis }\end{array}$ & $\begin{array}{l}\text { When one side's growth to drive the growth of the other side, the } \\
\text { growth of the other side will promote its own growth and the } \\
\text { driving effects are symmetric. }\end{array}$ \\
\hline
\end{tabular}

As Table 1 shows, the coevolution modes between the digital economy and real economy would express different features when the values of $\beta_{12}$ and $\beta_{21}$ vary. According to Equation (4), this article divides the process into two circumstances for analysis, specifically:

- Independent development of the digital economy and real economy 
The values of $\beta_{12}$ and $\beta_{21}$ in Equation (4) are both 0 under the condition, then there is no interaction between the digital economy and real economy, therefore, Equation (4) is adjusted to:

$$
\left\{\begin{array}{l}
\frac{d P_{1}(t)}{d t}=r_{1} P_{1}(t)\left[1-\frac{P_{1}(t)}{P_{m 1}}\right] \\
\frac{d P_{2}(t)}{d t}=r_{2} P_{2}(t)\left[1-\frac{P_{2}(t)}{P_{m 2}}\right]
\end{array}\right.
$$

Considering that the joint-system composed of the digital economy and real economy is affected by the external environment, the maximum growth capacity is a complex curve that changes over time. Assuming that $\Delta Z(t)$ is the change in external environmental impact in year $t, \delta_{1}$ and $\delta_{2}$ are the factors that affect the maximum growth capacity of the populations respectively. The maximum growth capacity of real economy changes from static $P_{m 1}$ to dynamic $P_{m 1}(t)$, the maximum growth capacity of the digital economy changes from static $P_{m 2}$ to dynamic $P_{m 2}(t)$, then the basic model evolves into:

$$
\left\{\begin{array}{l}
P_{m 1}(t)=P_{m 1}+\delta_{1} f_{1}(\Delta Z(t)) \\
P_{m 2}(t)=P_{m 2}+\delta_{2} f_{2}(\Delta Z(t))
\end{array}\right.
$$

In accordance with above Equations (5) and (6), the growth model in the circumstance that the two groups have no interaction in light of considering the influence of dynamic environmental factors is:

$$
\begin{gathered}
\left\{\begin{array}{c}
\frac{d P_{1}(t)}{d t}=r_{1} P_{1}(t)\left[1-\frac{P_{1}(t)}{P_{m 1}(t)}\right] \\
\frac{d P_{2}(t)}{d t}=r_{2} P_{2}(t)\left[1-\frac{P_{2}(t)}{P_{m 2}(t)}\right]
\end{array}\right. \\
\left\{\begin{array}{l}
P_{1}(t)=\frac{P_{m 1}(t)}{1+e^{-r_{1}\left(t-t_{0}\right)}\left(P_{m 1}(t)-P_{1}\left(t_{0}\right)\right) / P_{1}\left(t_{0}\right)} \\
P_{2}(t)=\frac{P_{m 2}(t)}{1+e^{-r_{2}\left(t-t_{0}\right)}\left(P_{m 2}(t)-P_{2}\left(t_{0}\right)\right) / P_{2}\left(t_{0}\right)}
\end{array}\right.
\end{gathered}
$$

- The interacting development of the digital economy and real economy

Considering the actual development process in the case, $\beta_{12}, \beta_{21}, P_{m 1}$, and $P_{m 2}$ are functions that vary with time and are affected by environmental factors. Hence, on the base of Equation (4), changing $\beta_{12}$ to $\beta_{12}(t), \beta_{21}$ to $\beta_{21}(t), P_{m 1}$ to $P_{m 1}(t)$ as well as $P_{m 2}$ to $P_{m 2}(t)$, and then the growth model based on the Logistic equation will be adjusted to:

$$
\left\{\begin{array}{l}
\frac{d P_{1}(t)}{d t}=r_{1} P_{1}(t)\left[1-\frac{P_{1}(t)}{P_{m 1}(t)}+\beta_{12}(t) \times \frac{P_{2}(t)}{P_{m 2}(t)}\right] \\
\frac{d P_{2}(t)}{d t}=r_{2} P_{2}(t)\left[1-\frac{P_{2}(t)}{P_{m 2}(t)}+\beta_{21}(t) \times \frac{P_{1}(t)}{P_{m 1}(t)}\right]
\end{array}\right.
$$

On the basis of Equation (9), the natural growth rate $(r)$ and the maximum environmental capacity $\left(P_{m}\right)$ show dynamic changes that are both affected by the environment as well as the mutual coevolution factors in the process of interactive development between populations. Therefore, we suppose that $\varepsilon_{1}(t)$ and $\varepsilon_{2}(t)$ are the dynamic natural growth rates respectively under the coevolution factor in year $t$. Moreover, $W_{1}(t)$ and $W_{2}(t)$ are the maximum environmental capacity in year $t$ respectively under the action of the coevolution factor; the above four variable equations can be described as follows:

$$
\begin{gathered}
\left\{\begin{array}{c}
\varepsilon_{1}(t)=r_{1}\left[1+\beta_{12}(t) \cdot \frac{P_{2}(t)}{P_{m 2}(t)}\right] \\
\varepsilon_{2}(t)=r_{2}\left[1+\beta_{21}(t) \cdot \frac{P_{1}(t)}{P_{m 1}(t)}\right]
\end{array}\right. \\
\left\{\begin{array}{l}
W_{1}(t)=P_{m 1}(t)\left[1+\beta_{12}(t) \cdot \frac{P_{2}(t)}{P_{m 2}(t)}\right] \\
W_{2}(t)=P_{m 2}(t)\left[1+\beta_{21}(t) \cdot \frac{P_{1}(t)}{P_{m 1}(t)}\right]
\end{array}\right.
\end{gathered}
$$


After incorporating Equations (10) and (11) into Equation (9), we could obtain the growth model below, while considering that the development of the digital economy and real economy is affected by the dynamic environment and the coevolution factors (as close to reality):

$$
\begin{gathered}
\left\{\begin{array}{c}
\frac{d P_{1}(t)}{d t}=\varepsilon_{1}(t) P_{1}(t)\left[1-\frac{P_{1}(t)}{W_{1}(t)}\right] \\
\frac{d P_{2}(t)}{d t}=\varepsilon_{2}(t) P_{2}(t)\left[1-\frac{P_{2}(t)}{W_{2}(t)}\right]
\end{array}\right. \\
\left\{\begin{array}{l}
P_{1}(t)=\frac{W_{1}(t)}{1+e^{-\varepsilon_{1}\left(t-t_{0}\right)}\left(W_{1}(t)-P_{1}\left(t_{0}\right)\right) / P_{1}\left(t_{0}\right)} \\
P_{2}(t)=\frac{W_{2}(t)}{1+e^{-\varepsilon_{2}\left(t-t_{0}\right)}\left(W_{2}(t)-P_{2}\left(t_{0}\right)\right) / P_{2}\left(t_{0}\right)}
\end{array}\right.
\end{gathered}
$$

\subsection{Parameter Estimation Method}

The natural growth rate (i.e., $\varepsilon_{1}(t)$ and $\left.\varepsilon_{1}(t)\right)$ and the maximum environmental capacity (i.e., $W_{1}(t)$ and $W_{2}(t)$ ) in the two populations growth models are all influenced by the two group coordination coefficients and change over time, which cannot be obtained through simple calculations. The article draws upon the dynamic and complex parameter processing methodology of Tang et al. (2009) in the population evolution process and adopts the four-steps method to estimate model parameters [27]:

Step one: Find the natural growth rate $\left(r_{1} \& r_{2}\right)$ and the maximum environmental capacity $\left(P_{m 1}(t) \& P_{m 2}(t)\right)$ of the two populations during the independent development; divide the evolution process of the digital economy and real economy in units of years (i.e.,: $\left.t \in\left[t_{i}, t_{i+1}\right](i=0,1,2 \cdots, n), \Delta t=1\right)$; the macro-evolution curves of the two population densities can be regarded as the connection of the micro-evolution curves in each time interval, as described in Figure 3:

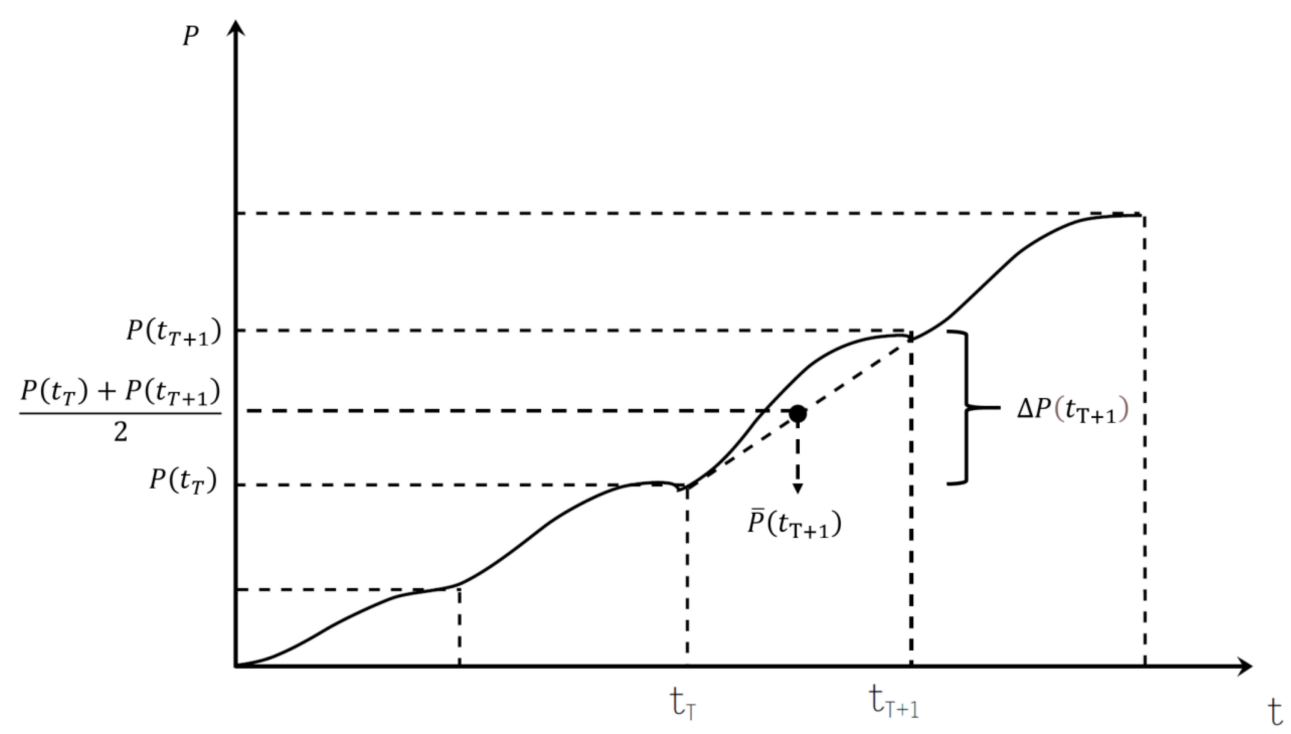

Figure 3. Logistic growth curve based on time cutting.

It is assumed via the processing that the population density increments in the unit time interval are $\Delta P_{1}\left(t_{i+1}\right)$ and $\Delta P_{2}\left(t_{i+1}\right)$, respectively; the average population densities are $\overline{P_{1}}\left(t_{i+1}\right)$ and $\overline{P_{2}}\left(t_{i+1}\right)$, respectively; and then the relationship between the population density increment and the population density average is in following:

$$
\left\{\begin{array}{l}
\Delta P_{1}\left(t_{i+1}\right)=P_{1}\left(t_{i+1}\right)-P_{1}\left(t_{i}\right) \\
\Delta P_{2}\left(t_{i+1}\right)=P_{2}\left(t_{i+1}\right)-P_{2}\left(t_{i}\right)
\end{array}\right.
$$




$$
\left\{\begin{array}{l}
\overline{P_{1}}\left(t_{i+1}\right)=\left[P_{1}\left(t_{i+1}\right)+P_{1}\left(t_{i}\right)\right] \div 2 \\
\overline{P_{2}}\left(t_{i+1}\right)=\left[P_{2}\left(t_{i+1}\right)+P_{2}\left(t_{i}\right)\right] \div 2
\end{array}\right.
$$

Accordingly, $\frac{d P_{1}(t+1)}{d t}$ and $\frac{d P_{1}(t+1)}{d t}$ can be calculated by using the following equation:

$$
\left\{\begin{array}{l}
\frac{d P_{1}(t+1)}{d t} \approx \Delta P_{1}\left(t_{i+1}\right) \\
\frac{d P_{2}(t+1)}{d t} \approx \Delta P_{2}\left(t_{i+1}\right)
\end{array}\right.
$$

On the basis of Equation (16), the slope of the population-independent growth curve is close to the slope of the straight line connecting the two ends of the interval in an interval with an annual unit. The population density in the micro interval can be the mean value in this interval, and then Equation (5) will change to:

$$
\left\{\begin{array}{l}
\Delta P_{1}\left(t_{i+1}\right)=r_{1} \overline{P_{1}}\left(t_{i+1}\right)\left[1-\frac{\overline{P_{1}}\left(t_{i+1}\right)}{P_{m 1}\left(t_{i+1}\right)}\right] \\
\Delta P_{2}\left(t_{i+1}\right)=r_{2} \overline{P_{2}}\left(t_{i+1}\right)\left[1-\frac{\overline{P_{2}}\left(t_{i+1}\right)}{P_{m 2}\left(t_{i+1}\right)}\right]
\end{array}\right.
$$

After sorting, the iterative formula for the maximum environmental capacity is as follows:

$$
\left\{\begin{array}{c}
P_{m 1}\left(t_{i+1}\right)=\frac{r_{1} \overline{P_{1}}\left(t_{i+1}\right)}{r_{1}-\frac{\Delta P_{1}\left(t_{i+1}\right)}{\bar{P}_{1}\left(t_{i+1}\right)}} \\
P_{m 2}\left(t_{i+1}\right)=\frac{r_{2} \overline{P_{2}}\left(t_{i+1}\right)}{r_{2}-\frac{\Delta P_{2}\left(t_{i+1}\right)}{\bar{P}_{2}\left(t_{i+1}\right)}}
\end{array}\right.
$$

Furthermore, since the maximum environmental capacity is always positive, the range of intrinsic growth rates of the two populations is:

$$
\left\{\begin{aligned}
r_{1} & >\frac{\Delta P_{1}\left(t_{i+1}\right)}{\bar{P}_{1}\left(t_{i+1}\right)} \\
r_{2} & >\frac{\Delta P_{2}\left(t_{i+1}\right)}{P_{2}\left(t_{i+1}\right)}
\end{aligned}\right.
$$

Given estimated values of $r_{1}$ and $r_{2}$ that are $\hat{r_{1}}$ and $\hat{r_{2}}$, the estimated values of maximum environmental capacity $\left(P_{m 1}\left(t_{i+1}\right) \& P_{m 2}\left(t_{i+1}\right)\right)$ are $\hat{P_{m 1}}\left(t_{i+1}\right)$ and $\hat{P_{m 2}}\left(t_{i+1}\right)$ respectively. Then, we can obtain the two populations density estimated values in $t_{i+1}$ (i.e., $\hat{P}_{1}\left(t_{i+1}\right)$ and $\left.\hat{P}_{2}\left(t_{i+1}\right)\right)$ after substituting into Equation (8); specifically as follows:

$$
\left\{\begin{array}{l}
\hat{P}_{1}\left(t_{i+1}\right)=\frac{\hat{P_{m 1}^{\wedge}}\left(t_{i+1}\right)}{1+e^{-r_{1}\left(t_{i+1}-t_{i}\right)}\left(\hat{\left.P_{m 1}\left(t_{i+1}\right)-P_{1}\left(t_{i}\right)\right) / P_{1}\left(t_{i}\right)}\right.} \\
\hat{P}_{2}\left(t_{i+1}\right)=\frac{\hat{P_{m 2}\left(t_{i+1}\right)}}{1+e^{-r_{2}\left(t_{i+1}-t_{i}\right)}\left(P_{m 2}^{\hat{n}}\left(t_{i+1}\right)-P_{2}\left(t_{i}\right)\right) / P_{2}\left(t_{i}\right)}
\end{array}\right.
$$

Pursuant to the given estimated values $\left(\hat{r_{1}} \& \hat{r_{2}}\right)$, the variance of the population density of real economy in each micro-interval (i.e., ${\hat{\sigma_{1}}}^{2}\left(t_{i+1}\right)$ and ${\hat{\sigma_{2}}}^{2}\left(t_{i+1}\right))$ is:

$$
\left\{\begin{array}{l}
{\hat{\sigma_{1}}}^{2}\left(t_{i+1}\right)=\sum_{i=0}^{n}\left[\hat{P}_{1}\left(t_{i+1}\right)-P_{1}\left(t_{i+1}\right)\right]^{2} \\
{\hat{\sigma_{2}}}^{2}\left(t_{i+1}\right)=\sum_{i=0}^{n}\left[\hat{P}_{2}\left(t_{i+1}\right)-P_{2}\left(t_{i+1}\right)\right]^{2}
\end{array}\right.
$$

The Nelder-Mead Simplex method [28] could be adopted to iteratively calculate infinitely close to the optimal point by Equation (21). When ${\hat{\sigma_{1}}}^{2}$ and ${\hat{\sigma_{2}}}^{2}$ reach the minimum value, we could get the optimum estimation value of $P_{m 1}\left(t_{i}\right), P_{m 2}\left(t_{i}\right), r_{1}, r_{2}$.

Step two: In the presence of the coevolution factors, calculating the natural growth rate $\left(\varepsilon_{1}(t) \& \varepsilon_{2}(t)\right)$ and the maximum environmental capacity $\left(W_{1}(t) \& W_{2}(t)\right)$. In units of years $\left(t \in\left[t_{i}, t_{i+1}\right](i=0,1,2 \ldots, n), \Delta t=1\right)$, the population density curve in the micro-range is similar to the slope of the straight line connecting the two ends of the interval. Furthermore, 
the population density value is very close to the straight line mean, then the Equation (12) can be evolved into the following:

$$
\left\{\begin{array}{l}
\Delta P_{1}\left(t_{i+1}\right)=\varepsilon_{1}\left(t_{i+1}\right) \overline{P_{1}}\left(t_{i+1}\right)\left[1-\frac{\overline{P_{1}}\left(t_{i+1}\right)}{W_{1}\left(t_{i+1}\right)}\right] \\
\Delta P_{2}\left(t_{i+1}\right)=\varepsilon_{2}\left(t_{i+1}\right) \overline{P_{2}}\left(t_{i+1}\right)\left[1-\frac{\overline{P_{2}}\left(t_{i+1}\right)}{W_{2}\left(t_{i+1}\right)}\right]
\end{array}\right.
$$

Then the maximum environmental capacity equation of the digital economy and real economy under the influence of coevolution factors can be obtained after sorting, as follows:

$$
\left\{\begin{array}{c}
W_{1}\left(t_{i+1}\right)=\frac{\varepsilon_{1}\left(t_{i+1}\right) \overline{P_{1}}\left(t_{i+1}\right)}{\varepsilon_{1}\left(t_{i+1}\right)-\frac{\Delta P_{1}\left(t_{i+1}\right)}{\overline{P_{1}}\left(t_{i+1}\right)}}, \varepsilon_{1}\left(t_{i+1}\right)>\frac{\Delta P_{1}\left(t_{i+1}\right)}{\overline{P_{1}}\left(t_{i+1}\right)} \\
W_{2}\left(t_{i+1}\right)=\frac{\varepsilon_{2}\left(t_{i+1}\right) \overline{P_{2}}\left(t_{i+1}\right)}{\varepsilon_{2}\left(t_{i+1}\right)-\frac{\Delta P_{2}\left(t_{i+1}\right)}{P_{2}\left(t_{i+1}\right)}}, \varepsilon_{2}\left(t_{i+1}\right)>\frac{\Delta P_{2}\left(t_{i+1}\right)}{\overline{P_{2}\left(t_{i+1}\right)}}
\end{array}\right.
$$

Similarly to the analysis of step one, given a set of estimated values of $\varepsilon_{1}\left(t_{i+1}\right)$ and $\varepsilon_{2}\left(t_{i+1}\right)$ (i.e., $\hat{\varepsilon}_{1}\left(t_{i+1}\right)$ and $\hat{\varepsilon}_{2}\left(t_{i+1}\right)$ ), we substitute into Equation (23) to calculate the estimated values of the maximum environmental capacity in each micro-range (i.e., $\hat{W}_{1}\left(t_{i+1}\right)$ and $\left.\hat{W}_{2}\left(t_{i+1}\right)\right)$, and then also substitute the maximum estimated environmental value into Equation (13) to get the estimated population density:

$$
\left\{\begin{array}{l}
\hat{P}_{1}\left(t_{i+1}\right)=\frac{\hat{W}_{1}\left(t_{i+1}\right)}{1+e^{-\varepsilon_{1}\left(t_{i+1}-t_{i}\right)}\left(\hat{W}_{1}\left(t_{i+1}\right)-P_{1}\left(t_{i}\right)\right) / P_{1}\left(t_{i}\right)} \\
\hat{P}_{2}\left(t_{i+1}\right)=\frac{\hat{\mathrm{W}}_{2}\left(t_{i+1}\right)}{1+e^{-\varepsilon_{2}\left(t_{i+1}-t_{i}\right)}\left(\hat{\mathrm{W}}_{2}\left(t_{i+1}\right)-P_{2}\left(t_{i}\right)\right) / P_{2}\left(t_{i}\right)}
\end{array}\right.
$$

Using the Nelder-Mead Simplex again to keep the estimated value close to the macro curve, the intrinsic natural growth rate and the corresponding maximum environmental capacity are obtained when the variance is minimum [28]. The specific equation is in the following:

$$
\left\{\begin{array}{l}
{\hat{\rho_{1}}}^{2}\left(t_{i+1}\right)=\sum_{i=0}^{n}\left[\hat{P}_{1}\left(t_{i+1}\right)-P_{1}\left(t_{i+1}\right)\right]^{2} \\
{\hat{\rho_{2}}}^{2}\left(t_{i+1}\right)=\sum_{i=0}^{n}\left[\hat{P}_{2}\left(t_{i+1}\right)-P_{2}\left(t_{i+1}\right)\right]^{2}
\end{array}\right.
$$

Step three: The above two steps have calculated the best estimated values of $P_{m 1}(t)$, $P_{m 2}(t), r_{1}, r_{2}, \varepsilon_{1}(t), \varepsilon_{2}(t), W_{1}(t), W_{2}(t)$ in each interval. In addition, we can get the calculation equation of $\beta_{12}(t)$ and $\beta_{21}(t)$ through Equations (10) and (11), as follows:

$$
\left\{\begin{array}{l}
\beta_{12}(t)=\left[\frac{\varepsilon_{1}(t)+W_{1}(t)}{P_{1}(t)+r_{1}}-1\right] \frac{P_{m 2}(t)}{P_{2}(t)} \\
\beta_{21}(t)=\left[\frac{\varepsilon_{2}(t)+W_{2}(t)}{P_{2}(t)+r_{2}}-1\right] \frac{P_{m 1}(t)}{P_{1}(t)}
\end{array}\right.
$$

Substituting the best estimated value of each variable calculated in the first two steps into Equation (26), then the best estimated value of $\beta_{12}(t)$ and $\beta_{21}(t)$ can be obtained.

Step four: In order to ensure that the estimation is objective, this article will first calculate the best estimated values of $\beta_{12}(t)$ and $\beta_{21}(t)$ from different population perspectives (e.g., value-added, fixed investment). Then, the entropy method is adopted to weigh $\beta_{12}(t)$ and $\beta_{21}(t)$. The specific process of entropy weighting is as follows $[29,30]$ :

- Standardizing the data

Supposing k-type indicators $\left(X_{1}, X_{2}, \ldots, X_{k}\right)$, where $X_{i}=\left\{x_{1}, x_{2}, \ldots, x_{n}\right\}$, has been standardized to be $Y_{1}, Y_{2}, \ldots, Y_{k}$; while $Y_{i j}=\frac{X_{i j}-\min \left(X_{i}\right)}{\max X_{i}-\min \left(X_{i}\right)}$.

- Finding the information entropy value of each indicator

The entropy of the index J is: 


$$
\begin{gathered}
E_{j}=-\frac{1}{\ln (\mathrm{n})} \sum_{i=1}^{n} p_{i j} \ln p_{i j} \\
p_{i j}=\frac{Y_{i j}}{\sum_{i=1}^{n} Y_{i j}}
\end{gathered}
$$

- Determining the weight of each indicator

Calculating the weight of each index $\left(W_{i}=\frac{1-E_{i}}{k-\sum E_{i}}\right)$ in accordance with the entropy value of each index $\left(E_{1}, E_{1}, \ldots, E_{k}\right)$ obtained in Step 2.

After the abovementioned method and process, we could get more objective best estimated values of $\beta_{12}(t)$ and $\beta_{21}(t)$.

\subsection{Variable Selection and Data Source}

\subsubsection{Variable Selection}

First of all, this article needs to select the data ranges and dimensions. Specifically, for the data range, this article controls the scope of the digital economy and real economy analysis to Mainland China in consideration of the timeliness and availability of data. For the data dimension, since the real economy and digital economy are not strictly biological populations, the current academics often adopt data such as the number of enterprises in the economy or industry, gross production value, industrial value added, investment amount, and number of employees as the industrial population biomass. Then the comprehensive index of population biomass could be obtained through standardized processing and weight distribution processing [31-37]. Based on the above-mentioned indicators, this article constructs the population density statistics from the two dimensions of economic benefit and social benefit complying with the principles of scientificity, systematization, and availability. The selection of secondary data indicators in each dimension are as shown in Table 2.

Table 2. Development index system of the digital economy and real economy.

\begin{tabular}{ccccc}
\hline Indicators & Index & Dimension & Definitions & Unit \\
\hline A1 & Economic benefits & Value Added & Value added of industries & Billion Yuan \\
A2 & & Fixed asset investment & Total investment in fixed assets & Billion Yuan \\
\hline B1 & Social benefits & Number of employees & Total employed persons & thousand people \\
B2 & & Number of market players & Number of enterprises or legal persons & person \\
\hline
\end{tabular}

On the selected indicator dimensions, it is also necessary to clarify the statistical boundary of the digital economy and real economy, then A1, A2, B1, and B2 values of each economy could be counted. Moreover, in order to observe the coevolution, real economy needs to be further divided into primary, secondary, and tertiary industries. This article comprehensively sorts out the concepts and analysis in the "G20 Digital Economy Development and Cooperation Initiative" issued by the G20 Hangzhou Summit in 2016; the "Defining and Measuring the Digital Economy" issued by the US Department of Commerce (BEA) in 2018; the definition of the digital economy by the British Economic and Social Research Institute; the "Digital Economy Plan" announced by Russia in 2017; and the definition of the digital economy by Chinese scholars, combined with China's latest "National Economic Industry Classification" (GB/T4754-2017); therefore, this article defines the boundaries of the digital economy and the three industries as follows [38-41]:

(1) The statistics of the digital economy include C39 (computer, communication and other electronic equipment manufacturing) and I63 I65 (information transmission, software and information technology service industry).

(2) The statistics of the real economy statistics include: 
For the primary industry, it includes agriculture, forestry, animal husbandry, and fishery (A01 A05).

For the secondary industry, it includes mining (B06 B10, B12), manufacturing (C13 C38, C40 C42), electricity, heat, popularity and water production and supply (D44 D46), and construction (E47 E50).

For the tertiary industry, it includes agricultural and sideline product processing (A06); mining professional and auxiliary activities (B11); metal products, machinery and equipment repair industry (C43); wholesale and retail industry (F51, F52); transportation, storage and postal industry (G53 G60); accommodation and catering industry (H61, H62); financial industry (J66 J69); real estate industry (K70); leasing and business service industry (L71, L72); scientific research and technical service industry (M73 M75); water conservancy, environment and public facilities management industry (N76 N79); resident service, repair and other service industry (O80 O82); culture, sports and entertainment industry (R86 R90); and public management, social security, and social organizations (S91 S96).

\subsubsection{Data Sources}

In pursuance of the above industry classifications and statistical boundary, the data in the study is basically from the 2005-2019 China Statistical Yearbook, 2005-2019 China National Economic and Social Development Statistical Bulletin, the 1st to 4th National Economic Census Communiqué as well as the "Annual Statistical Report on Software and Information Technology Services Industry" of 2018 and 2019 [42,43]. Meanwhile, taking into account the availability, timeliness and reliability of data, the following principles should be followed in the processing: First, the development data of various industries from 2005 to 2019 would be adopted to ensure the timeliness of data; second, in order to ensure availability, the added value of the three industries uses the data of enterprises above designated size and the number of market entities in the three industries is calculated by the number of legal persons, while the number of entities in the digital economy market is calculated by the number of enterprises; third, since the National Bureau of Statistics had no longer published the total output value of each segment of the industry from 2012, this article uses operating income as the added value of the computer, communications, and other electronic equipment manufacturing industries to ensure data consistency.

\section{Empirical Research}

\subsection{Analysis of the Coevolution Model}

This article uses Matlab software to calculate on a computer with a CPU frequency of 1992 MHZ and a memory of 8G. The specific process is as follows:

(1) The first step: Using Equations (14) to (21) to calculate the annual intrinsic growth rate and maximum environmental capacity under the independent development of the digital economy and real economy from 2005 to 2019. Since this part of the data is large and only used for subsequent calculations, the processing data is not displayed. If readers are interested, they can obtain this part of data from the authors.

(2) The second step: Calculating the population growth rate $(\varepsilon(t))$ and the maximum environmental capacity of the population $(W(t))$ under the interacting development between the digital economy and real economy from 2005 to 2019 by adopting the Equations (22) to (25). Similarly, since this part of the data is large and only used for subsequent calculations, the processing data is not displayed. If readers are interested, they can obtain this part of data from the authors.

(3) The third step: The intrinsic growth rate $\left(r_{1}, r_{2}\right)$ and the maximum environmental capacity $\left(P_{m 1}(t)\right.$ and $\left.P_{m 2}(t)\right)$ under the independent development can be obtained through the first step. Meanwhile, the natural growth rate $\left(\varepsilon_{1}(t)\right.$ and $\left.\varepsilon_{2}(t)\right)$ and the maximum environmental capacity $\left(W_{1}(t)\right.$ and $\left.W_{2}(t)\right)$ under the interacting development are obtained through the second step. Furthermore, the coevolution factors $\left(\beta_{12}(t)\right.$ and $\left.\beta_{21}(t)\right)$ of the digital economy and real economy in the four dimensions 
(A1, A2, B1, and B2) after incorporating the above parameters into Equation (26) can be identified.

(4) The fourth step: The entropy value can be obtained after standardizing the data of A1, A2, B1, and B2 respectively. The weight of each dimension index is determined by the entropy value as illustrated in Table 3:

Table 3. The weight indicators of the real economy (three industries) and digital economy.

\begin{tabular}{ccccc}
\hline Indicators & A1 & A2 & B1 & B2 \\
\hline Real economy & 0.2369 & 0.2550 & 0.1589 & 0.3492 \\
Primary industry & 0.1655 & 0.2813 & 0.1897 & 0.3636 \\
Secondary industry & 0.2598 & 0.2884 & 0.1267 & 0.3251 \\
Tertiary Industry & 0.2244 & 0.2306 & 0.2334 & 0.3115 \\
Digital economy & 0.1822 & 0.2960 & 0.1383 & 0.3835 \\
\hline
\end{tabular}

The $\beta_{12}(t)$ and $\beta_{21}(t)$ in the four dimensions (A1, A2, B1, and B2) are weighted by entropy weighting method. The specific data and the evolution trend are illustrated in the following Table 4 and Figure 4:

Table 4. The coevolution trend of the digital economy and real economy from 2005 to 2019.

\begin{tabular}{lll}
\hline Year & $\boldsymbol{\beta}_{\mathbf{1 2}}(\boldsymbol{t})$ & $\boldsymbol{\beta}_{\mathbf{2 1}}(\boldsymbol{t})$ \\
\hline 2005 & 7.3153 & 6.4296 \\
2006 & 6.7875 & 5.3037 \\
2007 & 3.8526 & 4.5708 \\
2008 & 2.5247 & 4.0273 \\
2009 & 1.3168 & 6.8785 \\
2010 & 2.2655 & 3.0160 \\
2011 & 1.4927 & 6.5439 \\
2012 & 2.1661 & 5.9663 \\
2013 & 2.4509 & 1.6565 \\
2014 & 2.0316 & 6.3297 \\
2015 & 3.8475 & 2.3099 \\
2016 & 3.0061 & 2.1403 \\
2017 & 3.6873 & 2.0617 \\
2018 & 3.2825 & 1.8208 \\
2019 & 2.0396 & 2.8411 \\
\hline
\end{tabular}

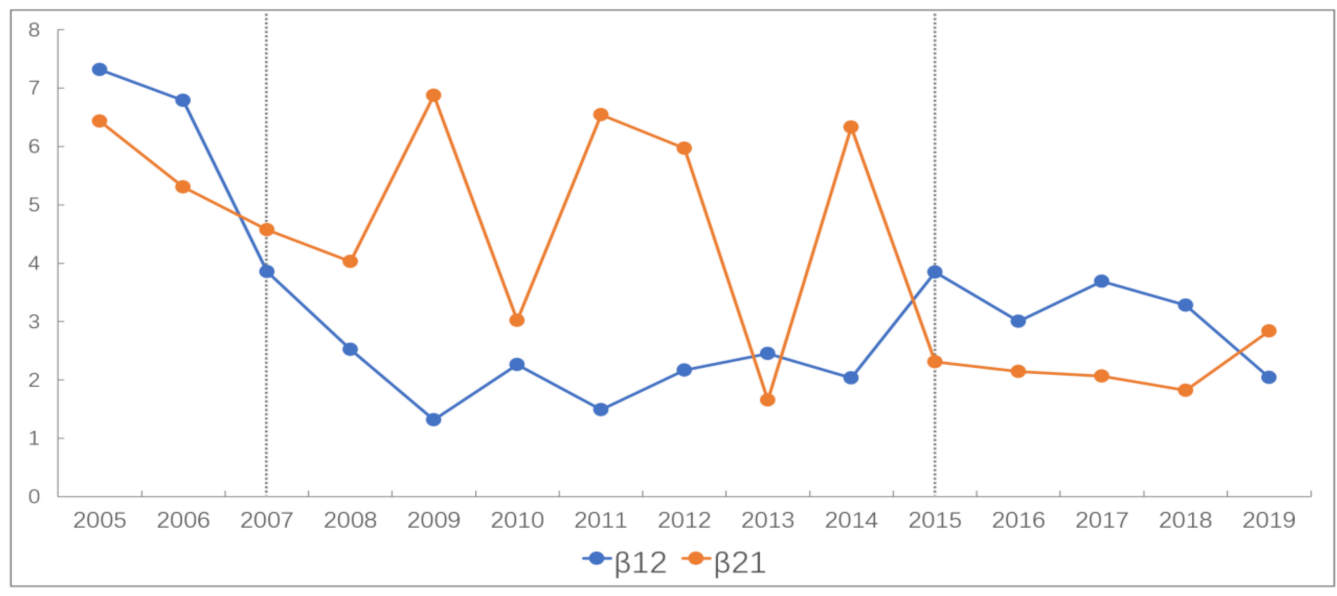

Figure 4. The coevolution trend of the digital economy and real economy from 2005 to 2019.

As Table 4 and Figure 4 show, $\beta_{12}(t)$ and $\beta_{21}(t)$ are both greater than 0 and $\beta_{12}(t) \neq \beta_{21}(t)$. In other words, the relationship between China's digital economy and real economy from 
2005 to 2019 basically followed the asymmetric reciprocal symbiosis mode. Specifically, it could be roughly divided into three stages: Firstly, when $\beta_{12}(t)>\beta_{21}(t)>0$ from 2005 to 2007, China's real economy's positive driving role in the digital economy was greater than the digital economy's enabling effect, while the scale and level of development of the digital economy were relatively low. Secondly, when $\beta_{21}(t)>\beta_{12}(t)>0$ from 2008 to 2015 (except 2013), the empowering effect of the digital economy on real economy was significantly higher than the positive driving effect of real economy on the digital economy. Then "digital industrialization" became the main driving force for the integrated development at this stage. Finally, when $\beta_{12}(t)>\beta_{21}(t)>0$ and the value of $\beta_{12}(t)$ and $\beta_{21}(t)$ continued to converge from 2016 to 2019, China's real economy's positive driving effect was slightly higher than the digital economy's enabling impacts. It can be observed that "industrial digitalization" became the main motivation in this stage to promote the convergence. Based on the analysis of the overall trend, this article further analyzes the coevolution trend of the digital economy and three industries, as shown in Tables 5-7 and Figures 5-7.

Table 5. The coevolution trend of the digital economy and primary industry from 2005 to 2019.

\begin{tabular}{ccc}
\hline Year & $\boldsymbol{\beta}_{\mathbf{1 2}}(\boldsymbol{t})$ & $\boldsymbol{\beta}_{\mathbf{2 1}}(\boldsymbol{t})$ \\
\hline 2005 & -5.0619 & 6.4296 \\
2006 & 13.6245 & 5.3037 \\
2007 & 8.2317 & 4.5708 \\
2008 & 2.6345 & 4.0273 \\
2009 & 2.8237 & 6.8785 \\
2010 & 4.3606 & 3.0160 \\
2011 & 1.8047 & 6.5439 \\
2012 & 2.2928 & 5.9663 \\
2013 & 3.5478 & 1.6565 \\
2014 & 2.6307 & 6.3297 \\
2015 & 4.2342 & 2.3099 \\
2016 & 2.9559 & 2.1403 \\
2017 & 4.8095 & 2.0617 \\
2018 & -0.4861 & 1.8208 \\
2019 & 3.8364 & 2.8411 \\
\hline
\end{tabular}

Table 6. The coevolution trend of the digital economy and secondary industry from 2005 to 2019.

\begin{tabular}{lll}
\hline Year & $\boldsymbol{\beta}_{\mathbf{1 2}}(\boldsymbol{t})$ & $\boldsymbol{\beta}_{\mathbf{2 1}}(\boldsymbol{t})$ \\
\hline 2005 & 3.3439 & 5.1772 \\
2006 & 7.1164 & 1.8030 \\
2007 & 4.7943 & 2.9180 \\
2008 & 2.9369 & 3.3632 \\
2009 & 1.9666 & 4.0554 \\
2010 & 3.1895 & 2.6195 \\
2011 & 1.7536 & 4.2862 \\
2012 & 2.9015 & 2.7613 \\
2013 & 1.8799 & 1.1121 \\
2014 & 2.6862 & 3.3220 \\
2015 & 3.4618 & 1.4820 \\
2016 & 3.1717 & 1.7669 \\
2017 & 1.9552 & 2.7489 \\
2018 & 0.1203 & 1.8556 \\
2019 & 2.7098 & 2.6012 \\
\hline
\end{tabular}


Table 7. The coevolution trend of the digital economy and tertiary industry from 2005 to 2019.

\begin{tabular}{lll}
\hline Year & $\boldsymbol{\beta}_{\mathbf{1 2}}(\boldsymbol{t})$ & $\boldsymbol{\beta}_{\mathbf{2 1}}(\boldsymbol{t})$ \\
\hline 2005 & 6.3600 & 4.5295 \\
2006 & 7.2471 & 2.0639 \\
2007 & 5.4725 & 2.5091 \\
2008 & 2.8159 & 3.1947 \\
2009 & 1.4688 & 7.1145 \\
2010 & 3.0172 & 3.0136 \\
2011 & 2.1114 & 3.7690 \\
2012 & 2.4176 & 3.1565 \\
2013 & 1.7159 & 2.8944 \\
2014 & 1.9620 & 4.6184 \\
2015 & 3.2341 & 2.5901 \\
2016 & 2.6249 & 2.4504 \\
2017 & 3.1632 & 2.5668 \\
2018 & 2.2756 & 2.0769 \\
2019 & 2.3962 & 2.6412 \\
\hline
\end{tabular}

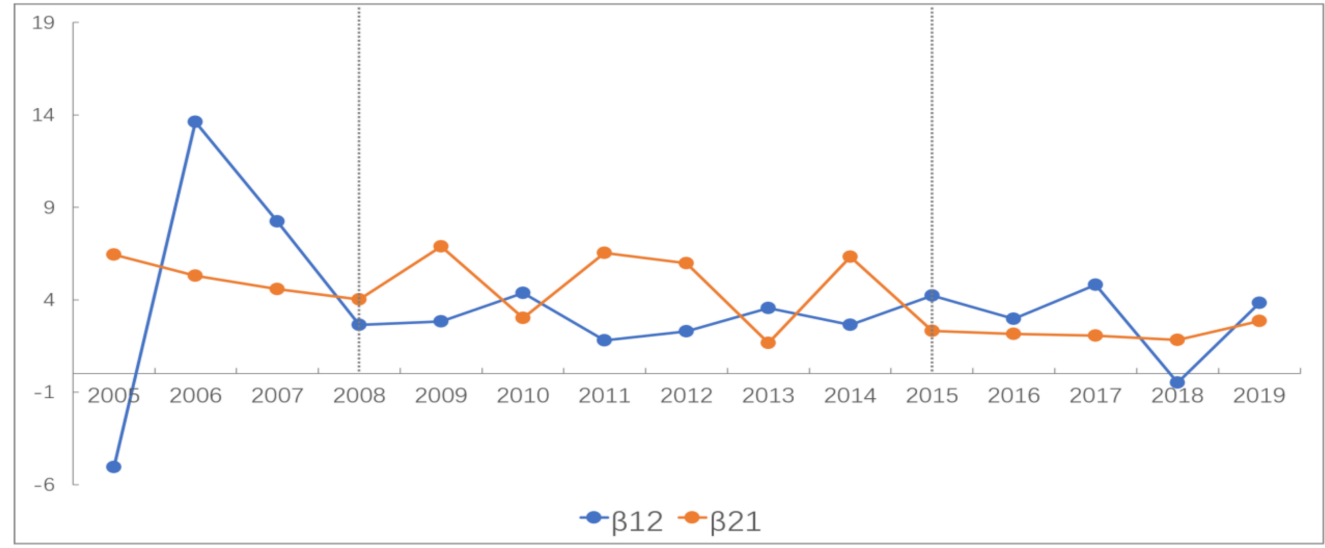

Figure 5. The coevolution trend of the digital economy and primary industry from 2005 to 2019.

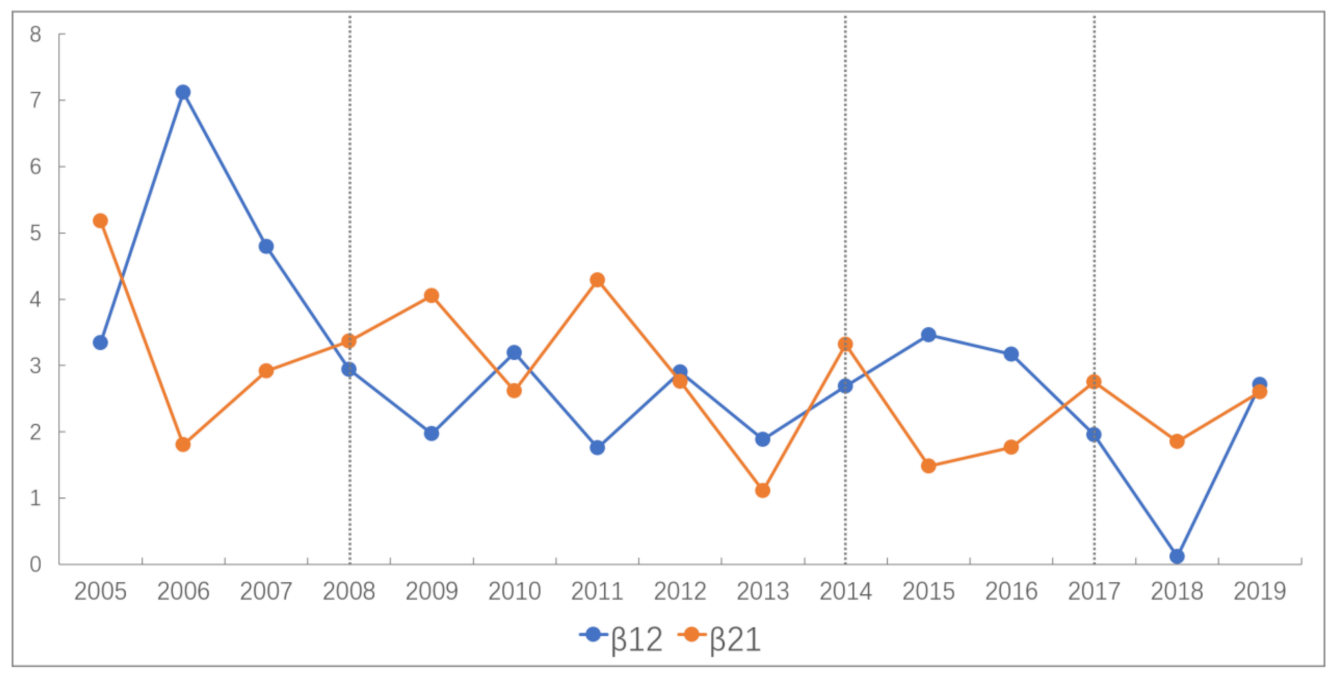

Figure 6. The coevolution trend of the digital economy and secondary industry from 2005 to 2019. 


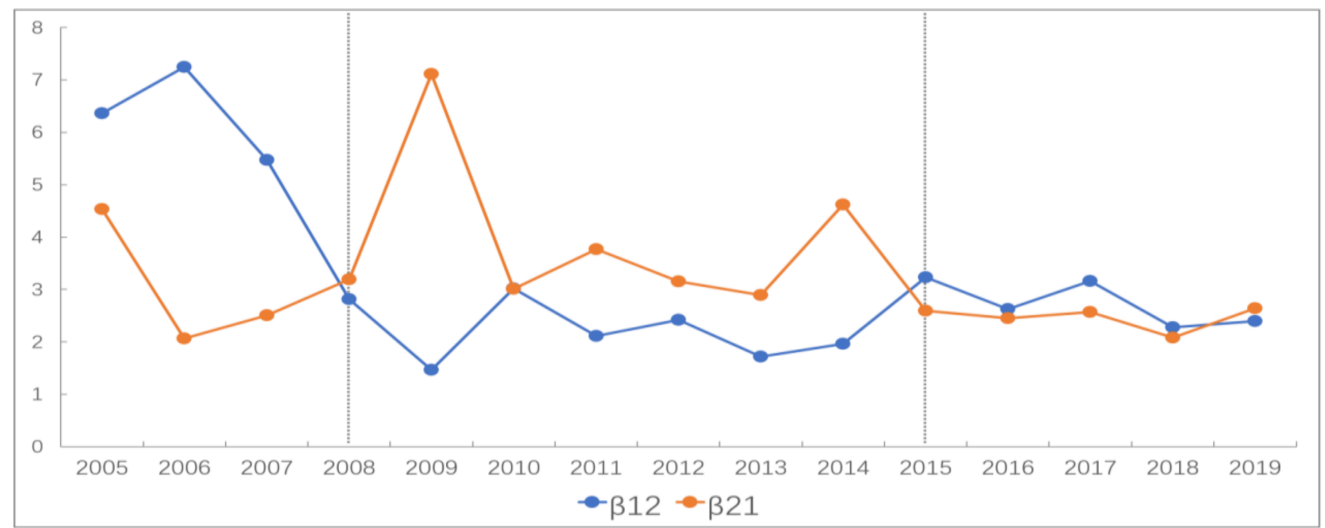

Figure 7. The coevolution trend of the digital economy and tertiary industry from 2005 to 2019.

Table 5 and Figure 5 could indicate that $\beta_{12}(t)$ and $\beta_{21}(t)$ are both greater than 0 and $\beta_{12}(t) \neq \beta_{21}(t)$ from 2005 to 2019. In this circumstance, the convergence of the digital economy and primary industry basically followed the asymmetric reciprocal symbiosis mode, however, the digital economy has a small empowering effect on primary industry. In particular, the coevolution process was comprised of three phases in general: The driving effect of primary industry on the digital economy was greater than the enabling effect of the digital economy from 2005 to 2008, while the value of $\beta_{12}(t)$ was overall greater than the value of $\beta_{21}(t)$. The coordination coefficient from 2009 to 2015 showed a dynamic trend of instability, viz. the convergence between the digital economy and primary industry was in an unstable state. Moreover, the driving effect of primary industry was once again higher than the enabling effect of the digital economy from 2016 to 2019. It could indicate that the convergence needed to closely integrate the characteristics of primary industry to engage in innovations and practices, which could fully stimulate the vitality of the digital economy and realize the mutual promotion of digital economy and primary industry.

It could be observed from Table 6 and Figure 6 that $\beta_{12}(t)$ and $\beta_{21}(t)$ are both greater than 0 and $\beta_{12}(t) \neq \beta_{21}(t)$ from 2005 to 2019 . Generally speaking, the convergence of the digital economy and secondary industry followed the asymmetric reciprocal symbiosis mode in the period. Specifically, the coevolution process could be divided into four phases below: From 2005 to 2008, secondary industry had a relatively stronger driving effect on the digital economy, which could effectively promote the development of the digital economy from the initial stage to the growth stage. The co-evolutionary factors (the values of $\beta_{12}(t)$ and $\beta_{21}(t)$ ) during the period from 2009 to 2014 fluctuated one after another while the empowerment effect of the digital economy was gradually increasing. Gradually, when the value of $\beta_{12}(t)$ was overall higher than the value of $\beta_{21}(t)$ from 2015 to 2017, the role of secondary industry in driving the digital economy was significantly greater than the enabling effect of the digital economy. Finally the convergence entered the "deep water" area from 2018 to 2019. On a positive note, the technological dividends in the previous convergence were fully released. Then, new digital infrastructure became the main driving force for the coordinated development of the digital economy and secondary industry. The enabling effect of the digital economy was again higher than the driving influence of secondary industry.

As Table 7 and Figure 7 illustrate, when $\beta_{12}(t)$ and $\beta_{21}(t)$ were both greater than 0 and $\beta_{12}(t) \neq \beta_{21}(t)$ from 2005 to 2019 , the convergence of the digital economy and tertiary industry evolved from the asymmetric reciprocal symbiosis mode to symmetric reciprocal symbiosis mode. Particularly, there were three stages roughly about the process. Firstly, when $\beta_{12}(t)>\beta_{21}(t)>0$ from 2005 to 2008 , tertiary industry had a relatively stronger driving effect with laying a solid foundation for the convergence and penetration. Secondly, it can be found from 2009 to 2014 that $\beta_{21}(t)>\beta_{12}(t)>0$. Meanwhile, the values of $\beta_{12}(t)$ and $\beta_{21}(t)$ evolved from a state of decline to a state of convergence in this stage while the empowerment effect of the digital economy was gradually increasing. Thirdly, from 2015 
to 2019 , as the development dividend of the consumer internet was slumping, the degree of convergence reached a relatively high level with further converged values of $\beta_{12}(t)$ and $\beta_{21}(t)$. In short, the mode of the digital economy and tertiary industry had also developed from the asymmetric reciprocal symbiosis mode to symmetric reciprocal symbiosis mode. Accordingly, it reflected that tertiary industry has the highest level of digitalization in the three industries.

\subsection{Simulation of the Coevolution Path of Digital Economy and Real Economy}

In order to further explore the trend under various co-evolutionary relationships, this article will focus on the simulation of $\beta_{12}(t)$ and $\beta_{21}(t)$ by assuming a time span of 50 years, which is based on Equation (9) with initial value of gross output (GDP) in 2019 as the initial value, the intrinsic growth rate of the population $\left(r_{1}=0.2182, r_{2}=0.3294\right)$, and the maximum environmental capacity $\left(P_{m 1}(t)=126,700, P_{m 2}(t)=17,049.3\right)$. The purpose of this is to simulate the development of various collaborative modes of the digital economy and real economy.

- Independent mode:

It can be identified from Figure 8 that the industrial value added increases gradually and stabilizes after reaching a peak on the premise of the same environmental capacity under the independent mode $\left(\beta_{12}(t)=\beta_{21}(t)=0\right)$. Furthermore, real economy would peak and stabilize at about the 20th year and the digital economy would peak and stabilize at about the 15 th year.

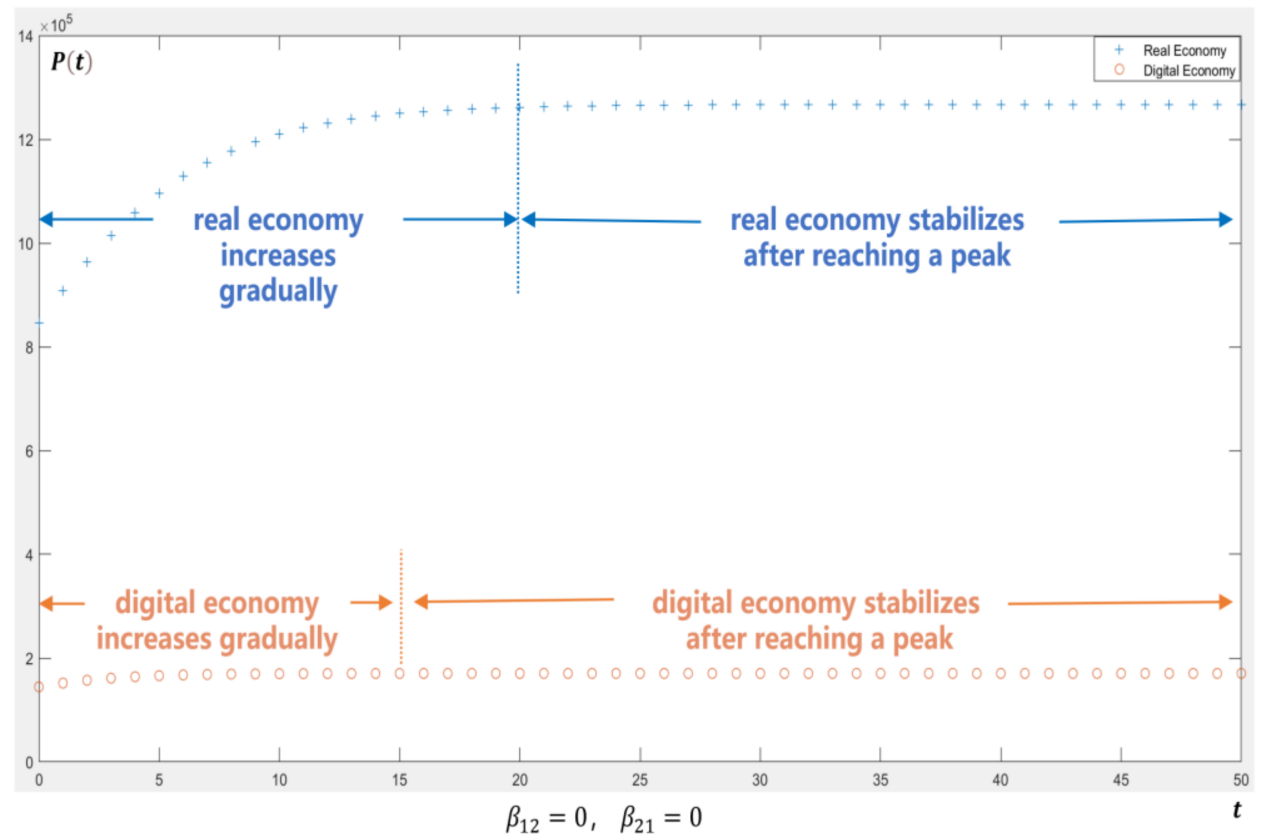

Figure 8. Simulation of independent mode of the digital economy and real economy (50 years).

- $\quad$ Competition mode:

As shown in Figure 9, the trend of industrial growth value is influenced by the relative strength of the coevolution factor in the competition mode $\left(\beta_{12}(t)<0, \beta_{21}(t)<0\right)$. When the degree of competition in real economy is higher than the digital economy $\left(\beta_{12}(t)=-0.5, \beta_{21}(t)=-1\right)$, the value added of real economy would initially decline due to the impact of competition, but it would stabilize to rebound and eventually reach its peak at about the 5th year. However, the digital economy is relatively in a competitive disadvantaged position, while the industrial value added gradually decreases and is going to die out. When the degree of competition in real economy is lower than the digital economy $\left(\beta_{12}(t)=-1, \beta_{21}(t)=-0.5\right)$, real economy is at a competitive disadvantage 
when the industrial value added continues to decline rapidly. Meanwhile, the digital economy is in a competitive position, in which the value added declines due to the influence of real economy competition in the early stage, but it would recover quickly and maintain a growth trend at about the 5 th year.
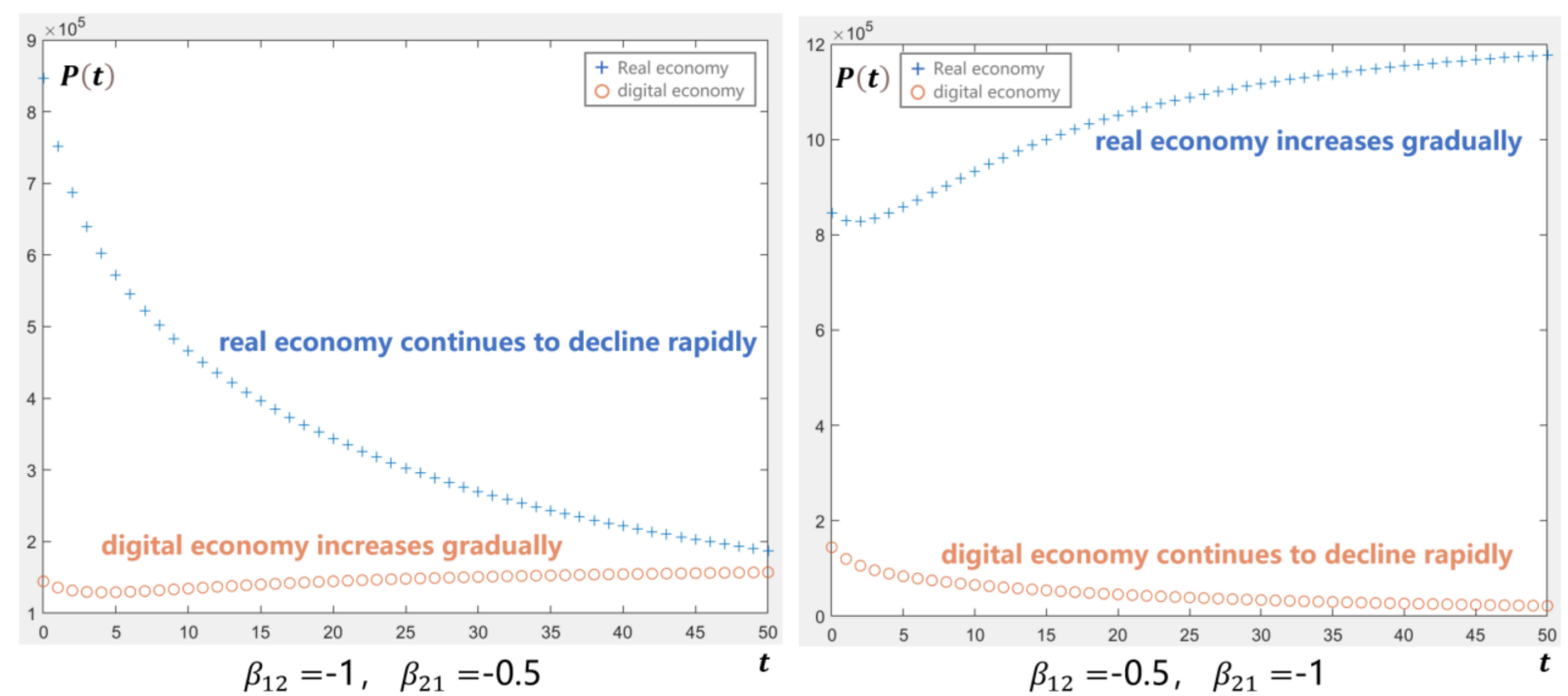

Figure 9. Simulation of competition mode of the digital economy and real economy (50 years).

\section{- $\quad$ Parasitism mode}

The above Figure 10 shows that, in the parasitism mode $\left(\beta_{12}(t)>0, \beta_{21}(t)<0\right.$ or $\left.\beta_{12}(t)<0 \beta_{21}(t)>0\right)$, the coevolution factors are that the positive side is parasitic on the other side, while the industrial added value of the positive factor would reach the level of the independent mode and the added value of the negative factor would continue to decline and risk of extinction would occur.
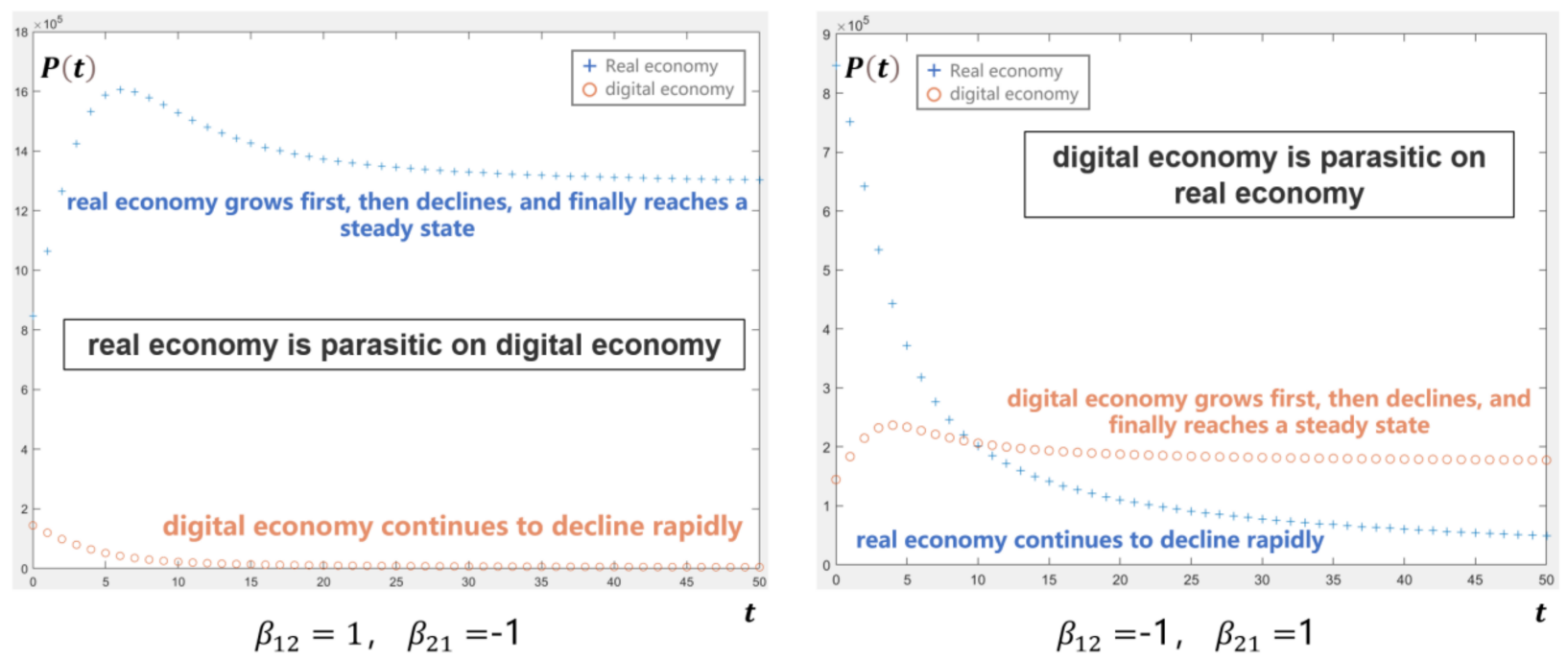

Figure 10. Simulation of parasitism mode of the digital economy and real economy (50 years).

- Commensalism symbiosis/Reverse commensalism symbiosis modes

It can be observed from Figures 11 and 12 that, in the commensalism symbiosis/ reverse commensalism symbiosis modes $\left(\beta_{12}(t)=0, \beta_{21}(t) \neq 0\right.$ or $\left.\beta_{12}(t) \neq 0, \beta_{21}(t)=0\right)$, the coevolution factors are positively (negatively) affected by the positive (negative) effect of the other side while the added value shows a rapid growth (decrease) trend in the short 
term, and the final value is higher (tending to die) compared with the independent mode. Surprisingly, the side whose coevolution factor is zero is not affected, and the final value added is the same as the value in the independent mode.
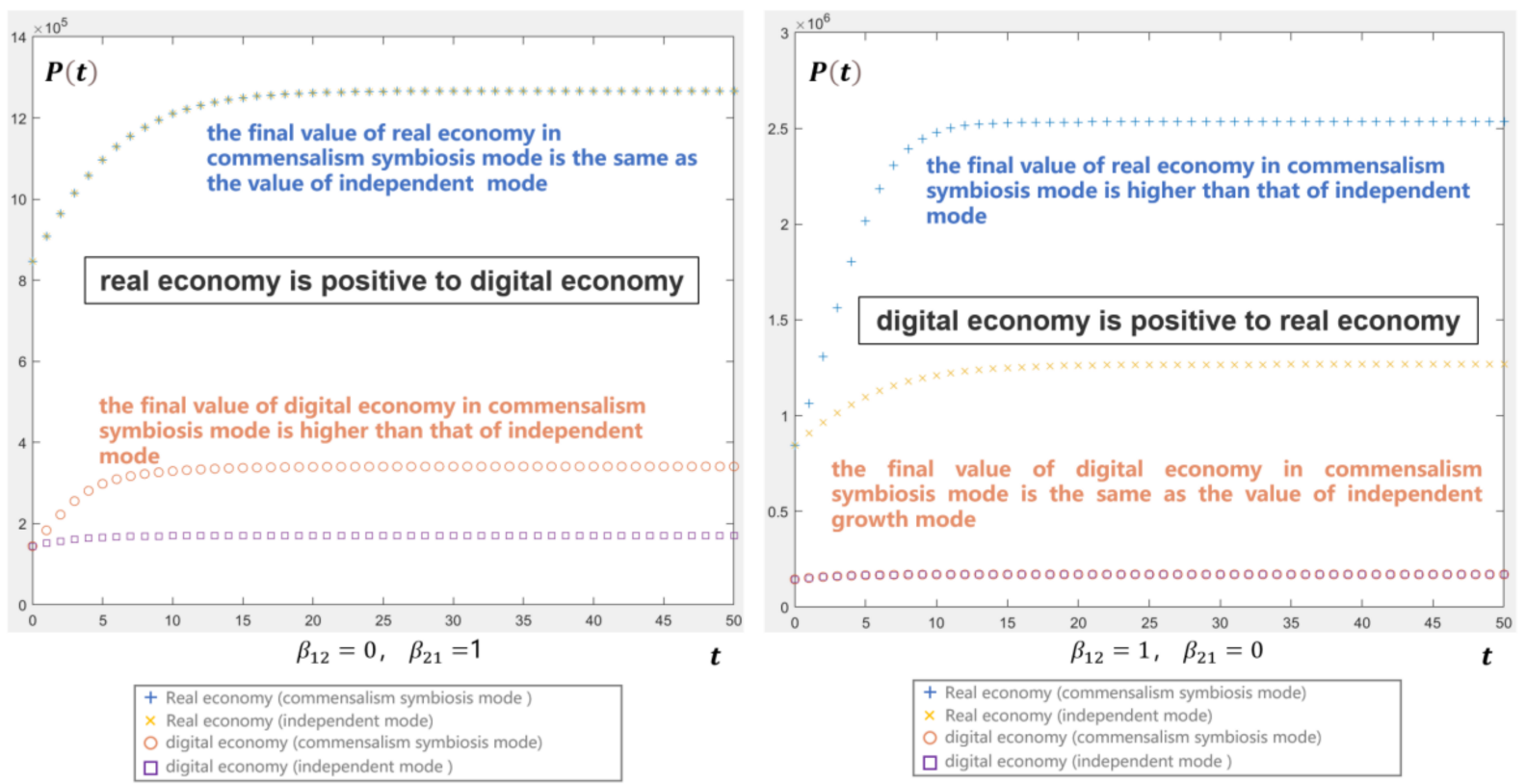

Figure 11. Simulation of commensalism symbiosis of the digital economy and real economy (50 years).
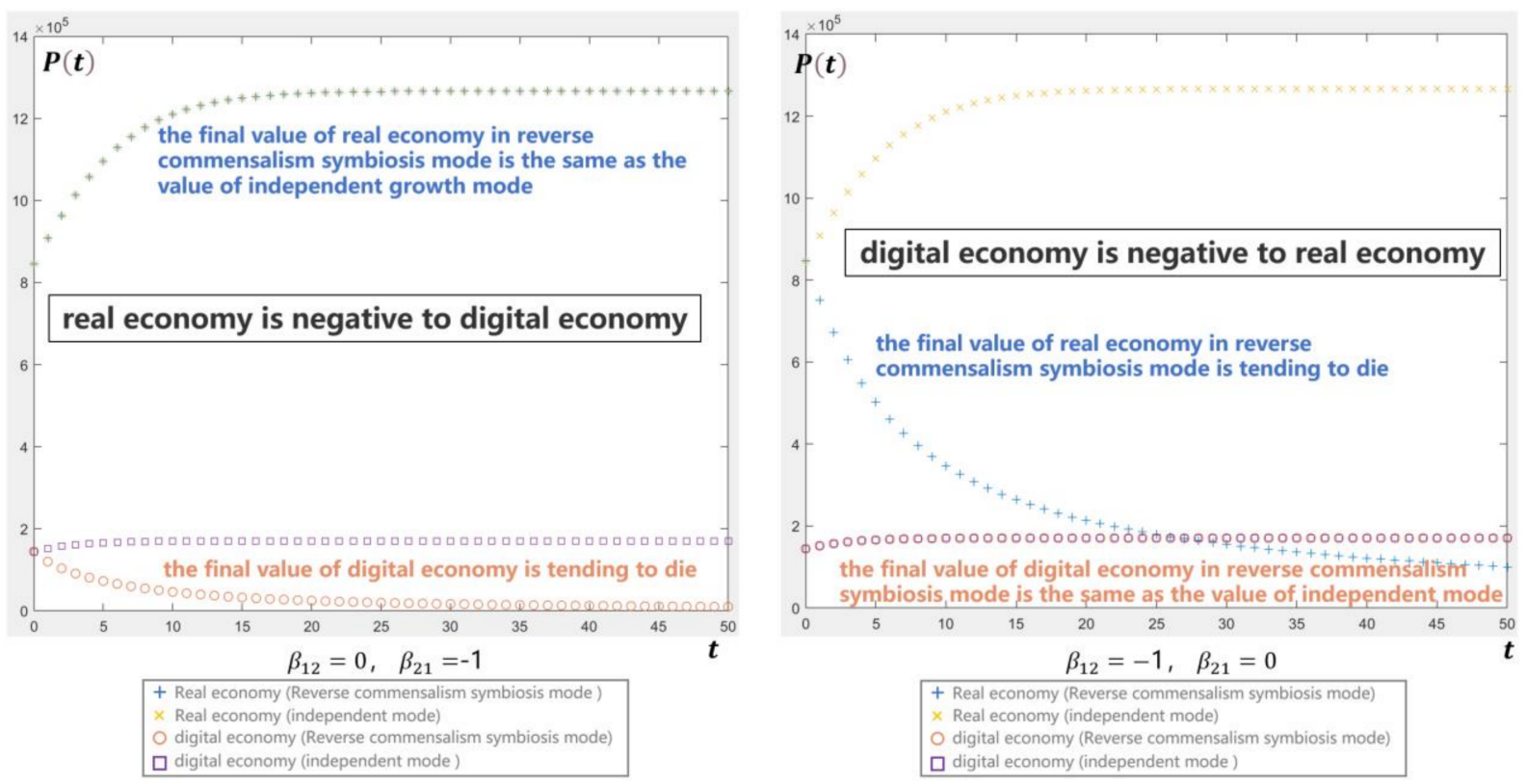

Figure 12. Simulation of reverse commensalism symbiosis of the digital economy and real economy (50 years).

- Asymmetric reciprocal symbiosis mode

As Figure 13 shows, the final value added in the asymmetric reciprocal symbiosis mode $\left(\beta_{12}(t)>0, \beta_{21}(t)>0, \beta_{12}(t) \neq \beta_{21}(t)\right)$ is higher than the value in the independent mode. Besides, the one with the greater coevolution factor has a greater increase in the value, benefiting from the stronger synergy effect of the other one. 

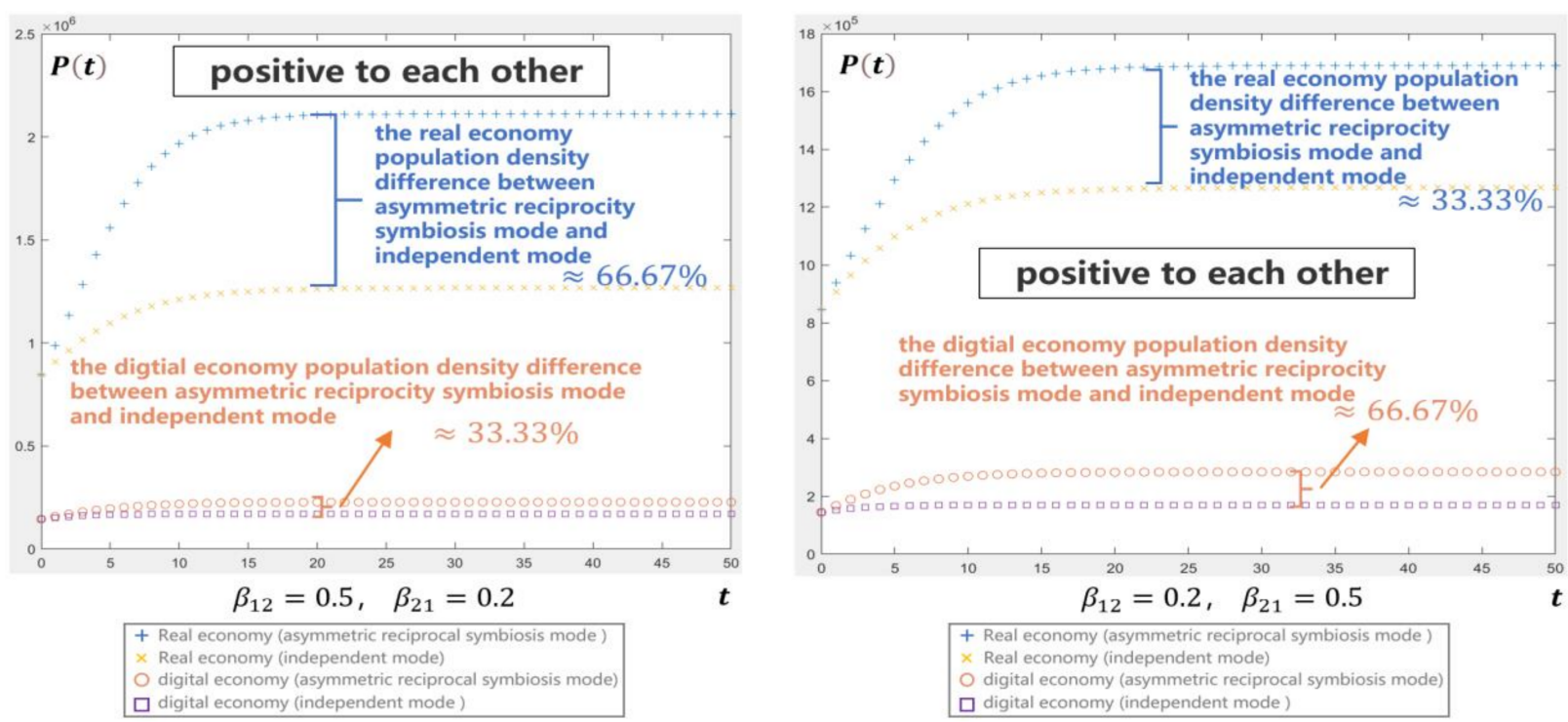

Figure 13. Simulation of asymmetric reciprocal symbiosis mode of the digital economy and real economy (50 years).

- Symmetric reciprocal symbiosis mode

As illustrated in Figure 14, in the symmetric reciprocal symbiosis mode $\left(\beta_{12}(t)>0\right.$, $\left.\beta_{21}(t)>0, \beta_{12}(t)=\beta_{21}(t)\right)$, the digital economy and real economy could achieve the peak value of industrial added value, which are higher than the values in the independent mode and the asymmetric reciprocity mode. In other words, the final sum of value added of the two major economies would reach the optimal state in the symmetric reciprocal symbiosis mode.

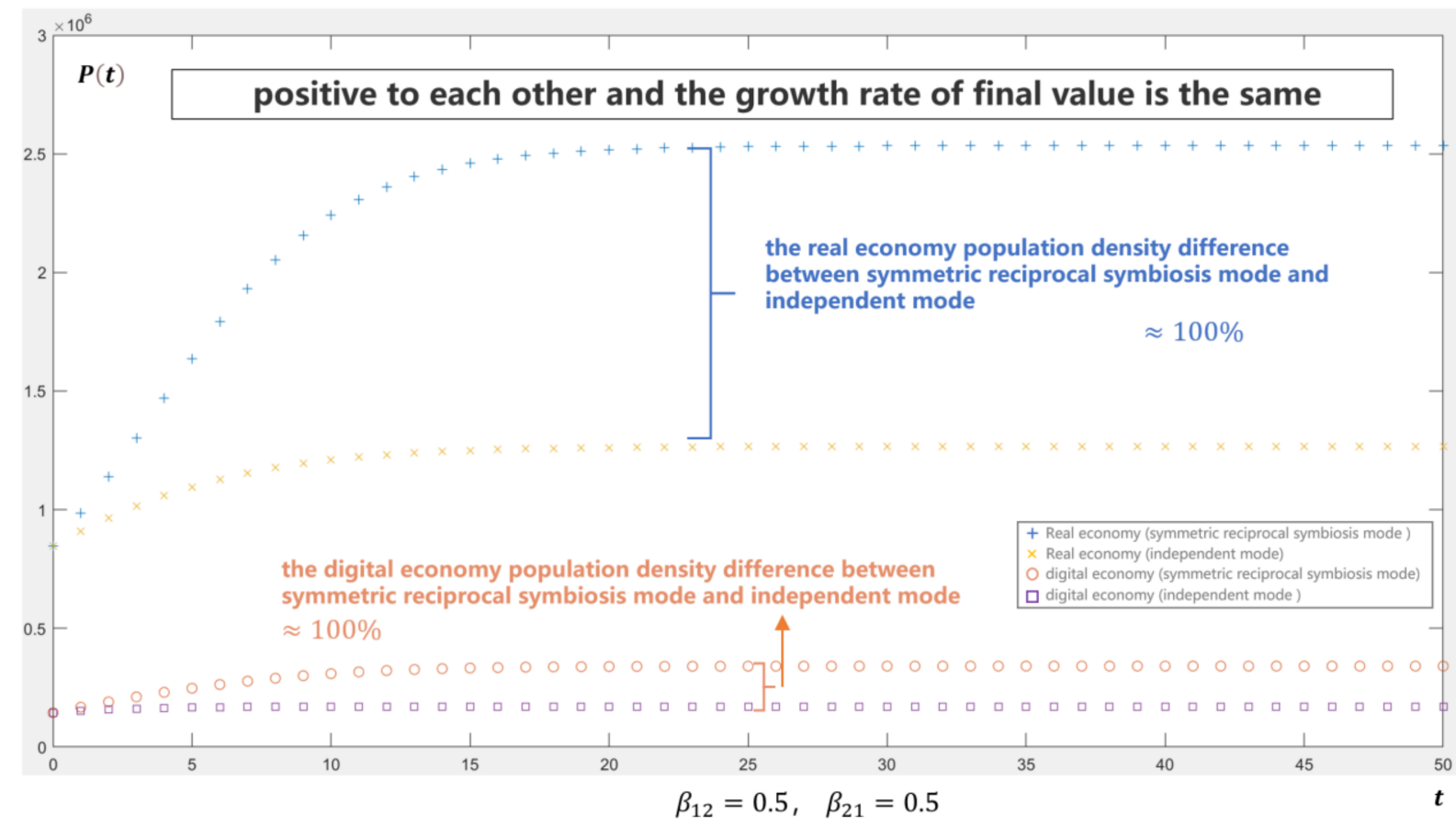

Figure 14. Simulation of symmetric reciprocal symbiosis mode of the digital economy and real economy (50 years).

\section{Conclusions}

Summing up, the following conclusions can be drawn through the above study: 
(1) Generally speaking, the relationship between the digital economy and the real economy during the period from 2005 to 2019 was the asymmetric reciprocal symbiosis mode. From 2005 to 2007, the real economy's positive driving role in the digital economy was greater than the digital economy's enabling role in the real economy when the scale and level of development of the digital economy were relatively low. From 2008 to 2015, the rapid growth of the digital economy benefited from the explosive growth of the consumer internet industry, which made much greater impacts on real economy comparing with the positive driving effect of the real economy. From 2016 to 2019 , the coevolution coefficient of the digital economy and real economy continued to converge, and the real economy's positive driving role was slightly higher than the digital economy's enabling effect.

(2) The relationship between the digital economy and primary industry was overall in the asymmetric reciprocal symbiosis mode during the period from 2005 to 2019. From 2005 to 2008, the driving effect of primary industry on the digital economy was greater than the enabling the role of digital economy. Gradually, the depth of the convergence of the digital economy and primary industry was insufficient from 2009 to 2015, therefore, the coordination coefficient showed an unstable and fluctuating state. From 2016 to 2019, the driving effect of primary industry was again higher, which indicated that the convergence needed to be in close connection with the characteristics of the primary industry to carry out the innovation and practice of digital transformation.

(3) During the period from 2005 to 2019, the overall relationship between the digital economy and secondary industry was also in the asymmetric reciprocal symbiosis mode. From 2005 to 2008, secondary industry played a stronger role in the digital economy, which effectively promoted the transition from the initial stage to the growth one. The co-evolutionary factors from 2009 to 2014 flipped back and forth while the enabling effect of the digital economy was gradually increasing. The role of secondary industry in driving the digital economy was significantly greater from 2015 to 2017; however, from 2018 to 2019 , the convergence entered the "deep water" area. The technological dividends in the previous development had been fully released and digital infrastructure had become the main driving force for the coordinated development of the digital economy and secondary industry.

(4) The relationship between the digital economy and tertiary industry evolved from an asymmetric reciprocal symbiosis mode to a symmetric reciprocal symbiosis mode from 2005 to 2019. Tertiary industry made a strong driving effect on the digital economy during the period from 2005 to 2008. However, the co-evolutionary factors changed from declining growth to convergence along with the increasing influences of the digital economy from 2009 to 2014 . Moreover, the convergence reached a high level, which further converged the co-evolutionary factors from 2015 to 2019. Thus, the previous mode developed into the symmetric reciprocal symbiosis mode.

(5) Through simulation analysis, it could be found that the digital economy and real economy did not interfere with each other and the increasing trend was stabilizing while they were in the independent mode. Nevertheless, in the competitive mode, parasitism mode or reverse commensalism symbiosis, one of both sides would always be negatively affected by the reverse effect of the other, which would be a declining risk of population density or even extinction. In other words, the effect of coevolution was not effective. Moreover, when the two major economies were in the commensalism symbiosis mode or the asymmetric reciprocity symbiosis mode, one of the two would be affected from the positive synergy to increase the population density with better coevolution effect. While in the symmetric reciprocal symbiosis mode, the final value added would increase more than the value in the asymmetric reciprocal symbiosis mode. Consequently, the symmetric reciprocal symbiosis mode should be the best mode for realizing the convergence of China's digital economy and real economy. 
Author Contributions: Conceptualization, G.X.; data curation, G.X.; formal analysis, G.X.; methodology, G.X.; writing-original draft, G.X.; writing-review and editing, G.X.; supervision, T.L.; visualization, Y.L. All authors have read and agreed to the published version of the manuscript.

Funding: This research received no external funding.

Institutional Review Board Statement: Not applicable.

Informed Consent Statement: Not applicable.

Data Availability Statement: Publicly available datasets were analyzed in this study. This data can be found here: http:/ / www.stats.gov.cn/tjsj/ndsj/ (accessed on 16 October 2020).

Conflicts of Interest: The authors declare no conflict of interest.

\section{References}

1. Hanna, N. Mastering Digital Transformation; Emerald Publishing: Bingley, UK, 2016.

2. Avi, G.; Catherine, T. Digital economics. J. Econ. Lit. 2019, 1, 3-43.

3. Martin, H.R. From Industrial Economics to Digital Economics: An Introduction to the Transition; ECLAC: Mexico City, Mexico, 2001.

4. Eric, B.; Nicolas, C. Internet and Digital Economics: Principles, Methods and Applications; Cambridge University Press: Cambridge, UK, 2007.

5. Tong, F.; Zhang, G. The Connotation Characteristics, Unique Advantages and Path Dependence of China's Development of Digital Economy. Science and Technology Management Research 2020, 40, 262-266.

6. Yang, X. Digital Economy: Economic Logic of In-depth Transition of Traditional Economy. J. Shenzhen Univ. (Humanit. Soc. Sci.) 2017, 34, 101-104.

7. OECD. OECD Digital Economy Outlook 2017; OECD Publishing: Paris, France, 2017.

8. Metcalfe, B. Metcalfe's Law: Network Becomes more Valuable as it Reaches More Users. InfoWorld 1995, 17, 53.

9. Yoffie, D.B. Competing in the Age of Digital Convergence (Hardcover); Harvard Business School Press: Boston, MA, USA, $1997 ;$ p. 1.

10. Uekusa, M. Mix of Communication and Information Industry. China Ind. Econ. 2001, 2, $24-27$.

11. Curran, C.S.; Broring, S.; Leker, J. Anticipating converging industries using publicly available data. Technol. Forecast. Soc. Chang. 2010, 77, 385-395. [CrossRef]

12. Curran, C.S.; Leker, J. Patent indicators for monitoring convergence-examples from NFF and ICT. Technol. Forecast. Soc. Chang. 2011, 78, 256-273. [CrossRef]

13. Yu, R.G.; Li, Y. The Impact of Industrial Convergence on the Policy of Industrial Organization. Financ. Trade Econ. 2004, 10, 18-22.

14. Yu, G.R.; Li, Y. Research on technology Innovation and Industry Integration. Product. Res. 2003, 6, $175-177$.

15. Yu, R.G. The classification of three industries and the trend of industry integration. Rev. Econ. Res. 1997, 25, 46-47.

16. Xie, K.; Xiao, J.; Zhou, X.; Wu, J. Quality of Integration of Industrialization and informatization in China: Theory and Demonstration. Zhongguo Xinxihua 2017, 4, 71-83.

17. Xie, K.; Xiao, J. Integration of Industrialization and informatization: A theoretical model. J. Sun Yatsen Univ. (Soc. Sci. Ed.) 2011, $51,210-216$.

18. Xiao, J.; Xie, K.; Zhou, X.; Wu, J. The Development Model of Informatization-Promoting-Industrialization. J. Sun Yatsen Univ. (Soc. Sci. Ed.) 2006, 46, 98-104.

19. Nelson, R.R. The Co-evolution of Technology, Industrial Structure, and Supporting Institutions. Ind. Corp. Chang. 1994, 3, 47-63. [CrossRef]

20. Murmann, J.P. Knowledge and Competitive Advantage: Knowledge and Competitive Advantage: The Coevolution of Firms, Technology, and National Institutions; Cambridge University Press: Cambridge, UK, 2003.

21. Huang, K. Comments on the Theory of Coevolution. J. China Univ. Geosci. (Soc. Sci. Ed.) 2008, 4, 97-101.

22. Li, D.; Xiang, B. Review on the co evolution theory of organization and environment. Foreign Econ. Manag. 2007, $29,9-17$.

23. Zhang, Q. An Empirical Study on the Co-Evolution of China'us Manufacturing Industry and Productive Service Industry; LiaoNing University: Shenyang, China, 2018.

24. Verhulst, P.F. Recherches mathématiques sur la loi d'accroissement de la population. Nouveaux Mémoires de l'Académie Royale des Sciences et Belles-Lettres de Bruxelles 1845, 1, 1-42.

25. Michael, G.; Steven, K. Time Paths in the Diffusion of Product Innovations. Econ. J. 1982, 92, 630-653.

26. Pang, B.H. Research About Symbiotic Evolutionary Model of Producer Services and Manufacturing Industry in China. Chin. J. Manag. Sci. 2012, 20, 176-183.

27. Tang, R.Q.; Xu, X.L.; He, Z.L. A Model and Empirical Study of the Symbiotic Develop-ment between the Producer-service Industry and the Manufacturing Industry. Nankai Bus. Rev. 2009, 12, 20-26.

28. Olsson, D.M.; Nelson, L.S. The Nelder-Mead simplex procedure for function minimization. Technometrics 1975, $17,45-51$. [CrossRef]

29. Ahn, B. Compatible weighting method with rank order centroid: Maximum entropy ordered weighted averaging approach. Eur. J. Oper. Res. 2011, 212, 552-559. [CrossRef] 
30. Citil, H.G. Important Notes for a Fuzzy Boundary Value Problem. Appl. Math. Nonlinear Sci. 2019, 4, 305-314. [CrossRef]

31. Jefferson, G.H.; Rawski, T.G.; Zhang, Y. Productivity growth and convergence across China's industrial economy. J. Chin. Econ. Bus. Stud. 2008, 6, 121-140. [CrossRef]

32. Kwon, O.; An, Y.; Kim, M.; Lee, C. Anticipating technology-driven industry convergence: Evidence from large-scale patent analysis. Technol. Anal. Strateg. Manag. 2020, 32, 363-378. [CrossRef]

33. Kim, N.; Lee, H.; Kim, W.; Lee, H.; Suh, J.H. Dynamic patterns of industry convergence: Evidence from a large amount of unstructured data. Res. Policy 2015, 44, 1734-1748. [CrossRef]

34. Yu, S. Research on the Relationship between Virtual Economy and Real Economy Development in China. J. Phys. Conf. Ser. 2019, 1237, 2.

35. Taddeo, R.; Simboli, A.; Morgante, A.; Erkman, S. The development of industrial symbiosis in existing contexts. Experiences from three Italian clusters. Ecol. Econ. 2017, 139, 55-67. [CrossRef]

36. Lawal, M.; Alwi, S.R.W.; Manan, Z.A.; Ho, W.S. Industrial symbiosis TOOLS-A review. J. Clean. Prod. 2020, $280,1-20$.

37. Li, Y.Y. Industry Convergence, Technology Progress and the Growth of Hi-Tech Industry. J. Converg. Inf. Technol. $2013,8,946-953$.

38. National Bureau of Statistics of China, Web of National Bureau of Statistics of China. National Bureau of Statistics of China. Available online: http:/ / www.stats.gov.cn/tjsj/tjbz/ (accessed on 15 October 2020).

39. G20 Research Group. G20 digital economy development and cooperation initiative. G20 Res. Group Univ. Tor. 2016, 1, 1-9.

40. Kevin, B.; Curtis, D.; Jolliff, W.; Nicholson, J.R.; Omohundro, R. Defining and measuring the digital economy. US Dep. Commer. Bur. Econ. Anal. Wash. DC 2018, 15, 1-25.

41. Zhang, D. A Brief Analysis of the Status Quo of Russian Digital Economy. Russ. Stud. 2018, 2, 130-158.

42. National Bureau of Statistics of China. Web of National Bureau of Statistics of China. Available online: http://www.stats.gov.cn/ tjsj/ndsj/ (accessed on 16 October 2020).

43. Ministry of Industry and Information Technology of the People's Republic of China. Annual Statistical Report on Software and Information Technology Services Industry of China. 2019. Available online: https://www.miit.gov.cn/jgsj/xxjsfzs/xyyx/art/20 20/art_7431516acb7944b38db842281c7eebba.html (accessed on 16 October 2020). 